Published in final edited form as:

Emotion. 2018 August ; 18(5): 707-724. doi:10.1037/emo0000339.

\title{
Dispositional negativity in the wild: Social environment governs momentary emotional experience
}

\author{
Alexander J. Shackman ${ }^{\star}, 1,3,4$, Jennifer S. Weinstein ${ }^{1}$, Stanton N. Hudja ${ }^{5}$, Conor D. \\ Bloomer $^{1}$, Matthew G. Barstead ${ }^{2}$, Andrew S. Fox ${ }^{6}$, and Edward P. Lemay Jr. ${ }^{*}, 1$ \\ ${ }^{1}$ Department of Psychology, University of Maryland, College Park, MD 20742 USA \\ ${ }^{2}$ Department of Human Development and Quantitative Methodology, University of Maryland, \\ College Park, MD 20742 USA \\ ${ }^{3}$ Neuroscience and Cognitive Science Program, University of Maryland, College Park, MD 20742 \\ USA \\ ${ }^{4}$ Maryland Neuroimaging Center, University of Maryland, College Park, MD 20742 USA \\ ${ }^{5}$ Krannert School of Management, Purdue University, West Lafayette, IN 47907 USA \\ ${ }^{6}$ Department of Psychology and California National Primate Research Center, University of \\ California, Davis, CA 95616 USA
}

\section{Abstract}

Dispositional negativity - the tendency to experience more frequent or intense negative emotions - is a fundamental dimension of temperament and personality. Elevated levels of dispositional negativity have profound consequences for public health and wealth, drawing the attention of researchers, clinicians, and policy makers. Yet, relatively little is known about the factors that govern the momentary expression of dispositional negativity in the real world. Here, we used smart phone-based experience-sampling to demonstrate that the social environment plays a central role in shaping the moment-by-moment emotional experience of 127 young adults selectively recruited to represent a broad spectrum of dispositional negativity. Results indicate that individuals with a more negative disposition derive much larger emotional benefits from the company of close companions - friends, romantic partners, and family members-and that these benefits reflect heightened feelings of social connection and acceptance. These results set the stage for developing improved interventions and provide new insights into the interaction of emotional traits and situations in the real world, close to clinically and practically important end-points.

Address Correspondence to: Alexander J. Shackman (shackman@umd.edu) or Edward P. Lemay, Jr. (elemay@umd.edu), BiologyPsychology Building, University of Maryland, College Park MD 20742 USA.

equal contributions

Contributions: A. S. Fox envisioned the study and provided theoretical guidance. A. J. Shackman, J. S. Weinstein, and S. N. Hudja designed the study. J. S. Weinstein coordinated data collection. J. S. Weinstein, S. N. Hudja, and C. D. Bloomer collected data. A. J. Shackman, J. S. Weinstein, and C. D. Bloomer processed data. E. P. Lemay developed the MLM analytic strategy and moderatedmediation model. E. P. Lemay, A. J. Shackman, and M. G. Barstead analyzed data. A. J. Shackman, E. P. Lemay, A. S. Fox, and M. G. Barstead interpreted data. A.J. Shackman, E.P. Lemay, J. S. Weinstein, and A. S. Fox wrote the paper. A.J. Shackman, A. S. Fox, and E. P. Lemay created figures. E. P. Lemay, A. J. Shackman, and M. G. Barstead created tables. A. J. Shackman funded and supervised all aspects of the study. All authors contributed to reviewing and revising the paper and approved the final version.

The authors declare no conflicts of interest. 


\section{Keywords}

anxiety; ecological momentary assessment (EMA); emotion; experience sampling; individual differences; negative affect; neuroticism; personality; temperament

\section{Introduction}

Dispositional negativity - the tendency to experience and express more intense, frequent, or persistent negative affect - is a fundamental dimension of childhood temperament and adult personality (Shackman, Tromp, et al., 2016). Elevated levels of dispositional negativity have profound consequences for public health and wealth, drawing the attention of researchers, clinicians, and policy makers. Yet, relatively little is known about the factors that govern the momentary expression of dispositional negativity in daily life.

\section{Dispositional Negativity}

Often termed neuroticism or negative emotionality, dispositional negativity is a trait-like phenotype that first emerges early in development, persists into adulthood, and reflects a combination of genetic and environmental factors (B. W. Roberts et al., 2017; B. W. Roberts \& Mroczek, 2008; Soto \& John, 2014; Vukasovic \& Bratko, 2015). Dispositional negativity is a broad construct that subsumes a number of other, more narrowly focused traits, including behavioral inhibition, neuroticism, self-criticism, trait anxiety, and low self-esteem (Judge, Erez, Bono, \& Thoresen, 2002; Mahaffey, Watson, Clark, \& Kotov, 2016; Shackman, Tromp, et al., 2016; Stanton, Rozek, Stasik, Ellickson-Larew, \& Watson, 2016; Watson, Stanton, \& Clark, in press).

Individual differences in dispositional negativity have important consequences for health, wealth, and wellbeing (Shackman, Kaplan, et al., 2016; Shackman, Tromp, et al., 2016). Individuals with a more negative disposition show lower levels of objective socioeconomic attainment (Damian, Su, Shanahan, Trautwein, \& Roberts, 2015; Ng, Eby, Sorensen, \& Feldman, 2005; Shanahan, Bauldry, Roberts, Macmillan, \& Russo, 2014) and experience lower levels of subjective well-being (Steel, Schmidt, \& Shultz, 2008). They are more likely to divorce (Karney \& Bradbury, 1995), to engage in unhealthy behaviors (Gale et al., 2016; Hakulinen, Hintsanen, et al., 2015; Kotov, Gamez, Schmidt, \& Watson, 2010), to develop emotional disorders (Hakulinen, Elovainio, et al., 2015; Jeronimus, Kotov, Riese, \& Ormel, 2016; Zinbarg et al., 2016), to become physically ill (Weston, Hill, \& Jackson, 2015), and to die prematurely (Chapman, Fiscella, Kawachi, \& Duberstein, 2010; Terracciano, Lockenhoff, Zonderman, Ferrucci, \& Costa, 2008; R. S. Wilson et al., 2005). As a consequence of these adverse outcomes, dispositional negativity imposes a tremendous burden on global healthcare systems (Goodwin, Hoven, Lyons, \& Stein, 2002; ten Have, Oldehinkel, Vollebergh, \& Ormel, 2005) and the economy (Cuijpers et al., 2010).

\section{Dispositional Negativity in the Real World}

Despite its profound consequences for health, wealth, and wellbeing, remarkably little is known about the situational factors that govern the expression and experience of dispositional negativity in the real world. To date, the vast majority of experience-sampling 
studies have focused on context-independent (i.e., aggregate) measures of positive and negative affect (e.g., Aldinger et al., 2014) ${ }^{1}$. A smaller number of studies have highlighted the importance of negative events, showing that dispositionally negative individuals are prone to heightened distress in response to hassles, conflicts, and other daily stressors (e.g., S. L. Gable, Reis, \& Elliot, 2000) ${ }^{2}$. For example, Bolger and Zuckerman (1995) used data gleaned from end-of-day diaries to show that young adults with a negative disposition (median split of $n=94$ ) report significantly higher levels of depression on days marked by interpersonal conflict. At present, the role of other contextual factors and the consequences for other facets of momentary experience remains rarely explored and poorly understood. Understanding the factors that govern the real-world expression of dispositional negativity is important. The identification of potentially modifiable targets, such as social context, has the potential to inform the development of scalable, low-cost intervention strategies for a wide range of important public problems, from divorce to disease, and would begin to address fundamental questions about the interaction of personality traits and situations (Caspi, Roberts, \& Shiner, 2005).

\section{The Present Study}

The widespread dissemination of smart phone technology affords new opportunities for understanding the factors that shape the expression of dispositional negativity in the real world or 'wild.' Here, we used smart phone-based ecological momentary assessment (EMA) to intensively sample key components of momentary emotional experience-including affect (positive and negative), social motivation (approach and avoidance), and appraisals about the future (pessimism and optimism) — in the daily lives of 127 young adults. We focused on young adulthood because it is a time of profound, often stressful developmental transitions (e.g., moving away from home, forging new social relationships; Alloy \& Abramson, 1999; Arnett, 2000; Hays \& Oxley, 1986). In fact, more than half of undergraduate students report overwhelming feelings of anxiety and more than a third report severe feelings of depression (American College Health Association, 2016), with many experiencing the first onset of psychopathology during this period (Beesdo, Pine, Lieb, \& Wittchen, 2010; Fava et al., 2010; Kessler et al., 2005). Because EMA data are captured in the real world, in real time (e.g., who are you with?), they circumvent the biases that distort retrospective reports, such as end-of-day diary entries, and can provide insights into how experience dynamically responds to changes in context (Supplementary Figure S1 and Supplementary Table 1) (Barrett, 1997; Lay, Gerstorf, Scott, Pauly, \& Hoppmann, in press; Stone, Shiffman, Atienza, $\&$ Nebeling, 2007). Subjects were selectively recruited from a much larger pool of previously screened individuals ( $n=2,501$; Figure $1 \mathrm{a}$ ), which enabled us to characterize

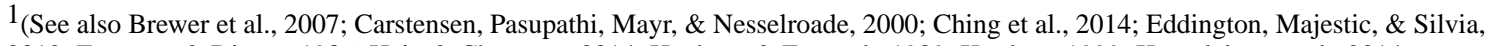
2012; Emmons \& Diener, 1986; Heiy \& Cheavens, 2014; Hepburn \& Eysenck, 1989; Kardum, 1999; Komulainen et al., 2014; Kuppens, Oravecz, \& Tuerlinckx, 2010; Kuppens, Van Mechelen, Nezlek, Dossche, \& Timmermans, 2007; Lay \& Hoppmann, 2014; McConville \& Cooper, 1999; Ode, Hilmert, Zielke, \& Robinson, 2010; Ong, Zautra, \& Reid, 2010; Park, Armeli, \& Tennen, 2004; Rusting \& Larsen, 1998; Schimmack, 2003; Sherry \& Hall, 2009; Skalina, Gunthert, Ahrens, \& Wenze, 2015; Tennen, Affleck, \& Zautra, 2006; Tong et al., 2006; Verduyn \& Brans, 2012; Watson, 1988; Williams, 1981, 1990; R. E. Wilson, Thompson, \& Vazire, in press).

2(See also Affleck, Tennen, Urrows, \& Higgins, 1994; Bolger, Delongis, Kessler, \& Wethington, 1989; Bolger \& Schilling, 1991; Bolger \& Zuckerman, 1995; Gunaydin, Selcuk, \& Ong, 2016; Hankin, Fraley, \& Abela, 2005; Howell \& Rodzon, 2011; Howland Armeli, Feinn, \& Tennen, 2017; Leger, Charles, Turiano, \& Almeida, 2016; Marco \& Suls, 1993; Mroczek \& Almeida, 2004; O'Hara, Armeli, Boynton, \& Tennen, 2014; Rodell \& Judge, 2009; Suls, Martin, \& David, 1998; Weltz, Armelia, Ford, \& Tennen, 2016; Zautra, Affleck, Tennen, Reich, \& Davis, 2005).
} 
relations between a broad spectrum of dispositional negativity (Figure 1b) and fluctuations in momentary experience across different real-world contexts for the first time.

We were particularly interested in understanding the impact of social context. Momentary experience is saturated with emotion, and emotion is profoundly social. Emotional experiences are routinely shared and dissected with close companions, including friends, romantic partners, and family members (Rime, 2009). Humans and other primates routinely seek the company of close companions in response to stressors (Cottrell \& Epley, 1977) and increased social engagement tends to promote positive affect (L. A. Clark \& Watson, 1988a, 1988b; Watson, 1988; Watson, Clark, McIntyre, \& Hamaker, 1992). Indeed, there is abundant evidence that close companions play a critical role in coping with stress and regulating negative affect (Bolger \& Eckenrode, 1991; Buote et al., 2007; Coan \& Sbarra, 2015; Marroquin, 2011; Myers, 1999; Zaki \& Williams, 2013). In fact, most attempts at emotion regulation occur in social contexts and more frequently involve close companions than strangers or acquaintances (Gross, Richards, \& John, 2006).

Using multilevel models (MLMs), we tested two competing predictions about the momentby-moment interaction of dispositional negativity and the social environment. One possibility is that individuals with a more negative disposition are more dependent on close companions for regulating their chronically elevated distress. Consistent with this possibility, dispositionally negative individuals retrospectively report that they often cope with stress by seeking the comfort, empathy, and emotional support of intimates (Bolger \& Zuckerman, 1995; Connor-Smith \& Flachsbart, 2007). This motivates the prediction that individuals with a more negative disposition critically rely on and derive larger emotional benefits (e.g., larger decrements in negative affect) from the company of close companions.

Another possibility is that more negative individuals fail to capitalize on available socioemotional support. Consistent with this prediction, individuals with a more negative disposition report lower levels of perceived social support (Bolger \& Eckenrode, 1991; Swickert, Hittner, \& Foster, 2010) and reduced satisfaction with their close companions (Dyrenforth, Kashy, Donnellan, \& Lucas, 2010; Slatcher \& Vazire, 2009; R. E. Wilson, Harris, \& Vazire, 2015). They tend to behave in ways that promote social discord and rejection (Creed \& Funder, 1998; Shackman, Tromp, et al., 2016); to experience more frequent or severe interpersonal conflict (Berry, Willingham, \& Thayer, 2000; Brock, Dindo, Simms, \& Clark, 2016; Buss, 1991; Donnellan, Larsen-Rife, \& Conger, 2005; Hutteman et al., 2014; Kendler, Gardner, \& Prescott, 2003; Mehl, Gosling, \& Pennebaker, 2006; Robins, Caspi, \& Moffitt, 2002); to over-react when conflict does occur (Bolger \& Schilling, 1991; Bolger \& Zuckerman, 1995); and to experience heightened loneliness (Mund \& Neyer, 2016; Pressman et al., 2005; Stokes, 1985). Taken together, these observations motivate the prediction that dispositionally negative individuals derive smaller emotional benefits (e.g., smaller decrements in negative affect) or even costs from the company of close companions.

Using a moderated mediation framework (Hayes, 2013), we also examined whether the interactive effects of dispositional negativity and the environment reflect momentary differences in perceived social connection. Work by our group and others suggests that heightened feelings of social connection, engagement, acceptance, and intimacy are a key 
feature of high-quality relationships and play an active role in promoting positive affect and buffering stress (Brown, Strauman, Barrantes-Vidal, Silvia, \& Kwapil, 2011; M. S. Clark \& Lemay, 2010; Coan \& Sbarra, 2015; Myers, 1999; Reis \& Shaver, 1989; Reis, Sheldon, Gable, Roscoe, \& Ryan, 2000). Conversely, low levels of closeness and heightened feelings of loneliness are key risk factors for physical and mental illness (Cacioppo, Grippo, London, Goossens, \& Cacioppo, 2015; Coan \& Sbarra, 2015; Editors, 2010).

\section{Method}

\section{Design Overview}

As part of an on-going program of research focused on the etiology of mood and anxiety disorders, we used well-established measures of dispositional negativity (see below) to screen a racially diverse sample of 2,501 young adults in exchange for course extra credit (66.1\% female; 56.7\% White, 16.0\% Asian, 14.7\% African American, 6.8\% Hispanic, 5.8\% Multiracial/Other; $M=19.8$ years, $S D=2.6$ years; Figure 1a). Data from the screening assessment were stratified by tertile (high, medium, low) and sex (male, female). For the EMA study, subjects were independently and randomly recruited via email from each of the resulting six strata, enabling us to sample a broad spectrum of dispositional negativity without gaps or discontinuities (Figure 1b), while balancing the inclusion of men and women. Subjects who lacked consistent access to a smart mobile phone were excluded. In practice this never occurred, presumably due to the high rate of smart phone ownership among young adults (i.e., $98.2 \%$ of the screening sample). At enrollment, subjects provided informed written consent, were familiarized with the EMA protocol, and re-completed the measures of dispositional negativity. Beginning the next day, subjects completed up to 10 EMA surveys per day for 7 days. At the end of the week, they were debriefed and compensated. All procedures were approved by the University of Maryland Institutional Review Board.

\section{Participants}

Six subjects were excluded from analyses due to insufficient compliance with the EMA protocol ( $<50 \%$ completed assessments; see below for additional details). The final EMA sample included 127 young adults (50.4\% female; 53.2\% White, $15.9 \%$ Asian, $13.5 \%$ African American, 6.3\% Hispanic, 11.1\% Multiracial/Other; $M=20.1$ years, $S D=1.6$ years) and captured a sizable portion of the dispositional-negativity spectrum, with standardized scores ranging from -1.97 to 2.24 (Figure 1b). The proportion of subjects drawn from each of the sampling strata did not differ $\left(\chi^{2}(5)=2.7, p=.75\right)$, indicating similar representation.

\section{Quantifying Dispositional Negativity}

We used psychometrically sound measures of neuroticism (Big Five Inventory Neuroticism; John, Naumann, \& Soto, 2008) and its anxious facet (International Personality Item Pool Trait Anxiety; Goldberg, 1999; Goldberg et al., 2006) to quantify individual differences in dispositional negativity. Subjects used a 1 (disagree strongly) to 5 (agree strongly) scale to rate themselves on a total of 18 items (e.g., depressed or blue, tense, worry, nervous, get distressed easily, fear for the worst, afraid of many things). At screening $(n=2,501)$, the neuroticism and anxiety scales were strongly correlated ( $r=.81)$ and reliable (as>.82). A 
composite measure of dispositional negativity was computed by taking the mean of the $z$ transformed scores (range of standardized scores: -2.55 to 2.92; $\mathrm{a}=.89$; Figure 1a). Among the 127 subjects who successfully completed the EMA study, variation in dispositional negativity displayed good test-retest reliability between the initial screening and a second assessment collected at the start of the week-long EMA study ( $r=.92 ; M=115.5$ days, $S D=61.0$ days). To minimize the influence of occasion-specific fluctuations in responding, hypothesis testing employed the average level of dispositional negativity across the two assessments (i.e., mean of standardized neuroticism and anxiety scales from both assessments; $a=.96$; Figure 1b).

\section{EMA Procedures}

SurveySignal (Hofmann \& Patel, 2015) was used to automatically deliver 10 text messages per day to each subject's smart phone. Messages were delivered between 8:30 AM and 11:00 PM, with 1-2 hours between successive messages ( $M=86.5$ minutes, $S D=14.7$ minutes). During weekday hours, messages were delivered during the 'passing periods' between scheduled university courses to maximize compliance. Messages contained a link to a secure on-line survey. Subjects were instructed to respond within 30 minutes of receiving the message and cautioned to avoid responding at unsafe or inconvenient moments (Latency: Median=3.03 $\mathrm{min}, S D=15.75 \mathrm{~min}$, Interquartile range $=0.85-15.35 \mathrm{~min})$. At enrollment, several well-established procedures were used to maximize compliance (Palmier-Claus et al., 2011). These procedures included: (1) delivering a test message to the subject's phone in the laboratory and confirming that they were able to successfully complete the on-line survey, (2) providing subjects with a 24/7 technical support number, (3) 24-hour and 72-hour check-in calls or emails, (4) real-time monitoring of compliance using the SurveySignal dashboard and re-contacting subjects showing low levels of compliance, and (5) monetary bonuses for increased compliance. In the final sample, EMA compliance was acceptable $(M=78.9 \%, S D=10.7 \%)$ and unrelated to dispositional negativity, $r(125)=-.04, p=.69^{3}$.

\section{EMA Survey}

The most salient social context was assessed using a forced-choice probe: Who are you with? (acquaintance(s), strangers, alone, close friend(s), romantic partner, or family). This was supplemented with two additional yes/no probes: Are you engaged in face-to-face conversation? and Are you engaged in a real-time digital (phone, text, Facebook, video) conversation? Key components of momentary emotional experience were rated using a 1 (not at all) to 5 (very) scale and included probes of positive affect (cheerful, happy, joyful), negative affect (anxious, nervous, worried), social approach (want to be with other people), social withdrawal (want to be alone), optimism (In the next hour, how positive do you guess the best thing is likely to be?), pessimism (In the next hour, how negative do you guess the worst thing is likely to be?), and social engagement (accepted, connected/engaged). Subjects were also provided with the opportunity to briefly describe the best and worst event in the prior hour (Supplementary Figure S1 and Supplementary Table 1).

\footnotetext{
${ }^{3}$ A series of MLM analyses indicated that individual differences in EMA compliance were not significantly related to any of the seven outcome measures (positive affect, negative affect, social approach, social withdrawal, optimism, pessimism, and social engagement), | $t \mid \mathrm{s}<1.57, p \mathrm{~s}>12$.
} 


\section{EMA Data Reduction}

Positive affect, negative affect, and social engagement items were averaged separately for each subject and survey. The resulting scales were highly reliable (as>.96). For social context analyses, assessments completed in the presence of close friends, romantic partners, or family members were re-coded as 'close' others, whereas assessments completed in the presence of acquaintances or strangers were re-coded as 'distant' others. This approach is conceptually similar to the distinction between 'strong' and 'weak' social connections (Granovetter, 1973).

\section{Hypothesis Testing Strategy}

Analyses were conducted using SPSS v. 23 (IBM Inc., Armonk, NY). Hypothesis testing focused on six closely related components of momentary emotional experience: affect (positive and negative), motivation (social approach and avoidance), and appraisals about the future (pessimism and optimism). Separate MLMs were computed for each of these outcome measures. Although our primary interest and strongest predictions naturally centered on negative affect, given our focus on dispositional negativity, we reasoned that testing all six measures would provide a more stringent test of our two competing predictions. That is, identifying a convergent pattern of results across the six measures would provide greater confidence than that afforded by any single test.

Hypothesis testing employed MLMs with momentary assessment data nested within subjects. Intercepts were free to vary across subjects. Moment-level predictors were meancentered separately for each subject. For illustrative purposes, conditional effects are depicted for extreme values $( \pm 1 S D)$ of dispositional negativity or perceived social connection (J. Cohen, Cohen, West, \& Aiken, 2003).

The interactive effects of Disposition and Social Context (Alone, Distant Others, Close Others) were assessed with MLMs incorporating five predictors: (a) mean-centered Disposition, (b) a dummy variable coding the presence of Distant Others (1=with distant; $0=$ not with distant), (c) a dummy variable coding the presence of Close Others (1=with close; $0=$ not with close), (d) a Disposition $\times$ Distant product term, and (e) a Disposition $\times$ Close product term. In these models, Alone served as the reference category. For example, the coefficient for the Close Others predictor captured the difference between being in the company of close companions versus being alone. Likewise, the coefficient for the Disposition $\times$ Close Others interaction indicates the degree to which the impact of dispositional negativity on momentary experience is conditional on being in the company of intimates compared to being alone. This can also be interpreted as the extent to which the impact of the situation (Close Others vs. Alone) on experience is conditional on disposition. Distant Others was used as the reference category in follow-up analyses. The same general approach was used to assess the influence of perceived social connection.

A moderated mediation framework (Hayes, 2013) was used to test whether the interactive effects of dispositional negativity and social context reflect momentary differences in perceived social connection. The significance of indirect effects was assessed using a Monte Carlo approach with 10,000 samples (Preacher \& Selig, 2012). 


\section{Results}

\section{Dispositional Negativity Reduces the Quality of Momentary Experience}

Higher levels of dispositional negativity had an adverse impact on the quality of momentary experience. In particular, individuals with a more negative disposition tended to experience elevated negative affect, heightened motivation to avoid others, and increased pessimism about the future, $t \mathrm{~s}>4.31, b \mathrm{~s}>.22, p s<.001$ (Supplementary Tables 2-3). Conversely, positive affect and optimism were both reduced, $t s<-2.22, b s<-.14, p s<.05$. A similar, but not significant effect was found for social approach motivation, $p=.12$. In short, dispositional negativity influences both positive and negative aspects of momentary experience, consistent with prior daily diary and EMA research (e.g., Aldinger et al., 2014; Ching et al., 2014; David, Green, Martin, \& Suls, 1997; S. L. Gable et al., 2000; Howell \& Rodzon, 2011; Jacobs et al., 2011; Komulainen et al., 2014; Leger et al., 2016; Ong et al., 2010; Skalina et al., 2015; Watson, 1988; Zautra et al., 2005).

\section{The Social Environment Matters-Preliminary Findings}

As a precursor to hypothesis testing, we assessed the amount of time that our sample invested in different social environments. As shown in Figure 2, subjects spent more than half their time in the company of others, consistent with other work in young adults (e.g., $\sim 41$ hours/week; Berry \& Hansen, 1996; Larson, 1990). Remarkably, on $68.4 \%$ of such occasions they were in the presence of close companions, suggesting that friends, romantic partners, and family members are especially well-positioned to influence the quality of momentary emotional experience. Indeed, a regression analysis revealed a dose-dependent effect of time spent with close companions. On average, individuals who spent more time in the company of close companions experienced lower levels of negative affect, higher levels of positive affect, and elevated optimism, $|x|(125)>.20, p s<.03$, with no significant effect on pessimism, $p=.15$. In contrast, individuals who spent more time alone experienced higher levels of negative affect, $I(125)=.20, p=.03$ (other effects, $p \mathrm{~s}>.11$ ).

Figure 2 also makes it clear that there are marked individual differences in the amount of time devoted to each social environment. For example, the inter-quartile range (depicted in green) for close others extends from $26.7 \%$ to $53.1 \%$ of assessments ( $\min =0 \%$; $\max =76 \%$ ). Importantly, dispositional negativity was not significantly related to the amount of time spent alone, with distant others, engaged in face-to-face conversation, or engaged in realtime digital interactions, such as texting, $|ı \mathrm{~s}|(125)<.12, p \mathrm{~s}>.19$. There was a trend for individuals with a more negative disposition to spend less time with close others, $I(125)=-$. $16, p>.08$. On balance, these findings suggest that young adults with elevated levels of dispositional negativity are socially active, not isolated, and spend considerable time in the company of intimates. This is consistent with work indicating little to no effect of dispositional negativity on social network size or density (Asendorpf \& Wilpers, 1998; Jensen-Campbell et al., 2002; Molho, Roberts, de Vries, \& Pollet, 2016; S. G. B. Roberts, Wilson, Fedurek, \& Dunbar, 2008; Selfhout et al., 2010; Totterdell, Holman, \& Hukin, 2008; Wagner, Ludtke, Roberts, \& Trautwein, 2014; Zhu, Woo, Porter, \& Brzezinski, 2013), the likelihood of developing friendships in young adulthood (Selfhout et al., 2010), the 
frequency of social interactions (Watson et al., 1992), or the frequency of desirable daily events with family and friends (David et al., 1997).

\section{Close Companions Enhance the Quality of Momentary Experience}

Consistent with our preliminary results, MLM analyses provided additional evidence that the social environment is a key determinant of intra-individual differences in momentary emotional experience (Figure 3 and Table 1). Relative to solitary contexts, the presence of close companions was associated with significantly lower levels of negative affect, social avoidance, and pessimism, $p s<.001$. Likewise, being in the company of close companions was associated with higher levels of positive affect, social approach, and optimism, $p s<.001$, replicating and extending the results of prior diary (Kahneman, Krueger, Schkade, Schwarz, \& Stone, 2004; Krueger, Kahneman, Schkade, Schwartz, \& Stone, 2009; Watson, 1988; Watson et al., 1992) and EMA studies (Csikszentmihalyi \& Hunter, 2003; Larson, 1990; Weinstein \& Mermelstein, 2007). A similar, but weaker pattern of effects was found for distant companions - only three of the six outcome measures were significant (Table 1). Follow-up analyses revealed that, relative to distant others, the company of close companions is associated with significant decrements in the three measures of negative experience and significant increments in the three measures of positive experience, $p s<.001$. This pattern of findings underscores the potent effects of close companions on real-world emotional experience.

\section{The Impact of Dispositional Negativity on Momentary Experience Strongly Depends on Social Context}

MLM analyses also demonstrated that the adverse impact of dispositional negativity on momentary experience is conditional on the social environment (Figure 3). In particular, individuals with higher levels of dispositional negativity reap much larger emotional benefits from the company of close companions when compared to assessments when they were alone or when compared to those with low levels of dispositional negativity ( $p s<.05$ for all six outcome measures; Tables 1 and 2). These effects were specific to close companions. None of the Disposition $\times$ Distant Others interactions were significant in the omnibus model (Table 1 ) and the Disposition $\times$ Close Others interaction remained significant for all six outcome measures when we incorporated Distant Others as the reference category, $p s<.02$. Taken together, these observations show that close companions are an important and beneficial governor of momentary emotional experience for individuals with a more negative disposition, consistent with our first competing prediction. 4

\section{The Impact of Close Companions Reflects Heightened Feelings of Social Connection Momentary fluctuations in the social environment determine perceived social connection-The results described so far indicate that close companions-friends, romantic partners, and family members—-have a deeply positive influence on momentary experience and that this is particularly evident for individuals with a more negative}

\footnotetext{
${ }^{4}$ Control analyses indicated that these effects were not due to differential contact with close companions. When we expanded the MLM to include the frequency of assessments with Close Others and the frequency of assessments with Distant Others (including appropriate product terms), the Disposition $\times$ Close Others interaction remained significant for all six outcome measures, $p s<.02$.
} 
disposition. But does this reflect heightened feelings of social connection, engagement, and acceptance? Consistent with this possibility, preliminary MLM analyses showed that fluctuations in the social environment parametrically determine the degree of perceived social connection (i.e., Close Others > Distant Others > Alone)—subjects felt more connected in the company of intimates compared to distant others and more connected in the company of distant others compared to being alone $(t \mathrm{~s}>11.86, b \mathrm{~s}>.31, p s<.001)$.

Individuals with a more negative disposition experience amplified feelings of social connection with close companions-Next, we used a moderated mediation framework to test whether the joint influence of dispositional negativity and social context on momentary experience reflects differences in perceived social connection (Figure 4) (Hayes, 2013). Put another way, individuals with a more negative disposition derive significantly larger emotional benefits from the company of intimates-but can this be explained by heightened feelings of social connection?

As a first step, we tested whether dispositional negativity and social context jointly determine feelings of social connection (Disposition $\times$ Context $\rightarrow$ Connection; path $b$ in Figure 4). In fact, both the Disposition $\times$ Close $(t=-2.15, b=-.06, p<.05)$ and Disposition $\times$ Distant ( $t=6.78, b=.16, p<.001)$ interactions were significant $(|t s|>2.14,|b s|>.05, p s<.05$; Figure 5). Higher levels of dispositional negativity are associated with lower levels of social connection when alone (white bars in Figure 5) or with distant others (gray bars in Figure 5; $t s<-4.36, b s<-.28, p s<.001)$. This detrimental effect is nearly abolished in the company of close others (black bars in Figure 5; $t=-1.95, b=-.13, p=.053$ ). Importantly, while the company of close companions is associated with heightened feelings of social connection (compared to being alone), this effect was much stronger for individuals with high compared to low levels of dispositional negativity (black and white bars in Figure 5; $t=30.19, b=.96$, $p<.001$ vs. $t=21.22, b=.65, p<.001)$.

Individuals with a more negative disposition experience attenuated feelings of social connection with distant companions-Interestingly, this pattern was reversed for distant others (gray and white bars in Figure 5). On average, the presence of distant others was associated with increased feelings of social connection relative to solitary contexts, but here the effect was weaker for individuals with high levels of dispositional negativity compared to those with low levels ( $t=7.21, b=.26, p<.001$ vs. $t=9.71, b=.38, p<$. 001). To further clarify the specificity of these effects, we recomputed the MLM using close others as the reference group. This revealed a significant Disposition $\times$ Distant interaction ( $t=-7.71, b=-.22, p<.001)$, indicating that the benefits of close (compared to distant) companions are magnified for individuals with a more negative disposition. Collectively, these results indicate that individuals with a more negative disposition are hyper-sensitive to some aspects of the social environment, experiencing amplified feelings of social connection in the company of intimates and attenuated feelings of social connection in the presence of acquaintances and strangers.

\section{Perceived social connection moderates the impact of dispositional negativity} on momentary experience-Next, we tested whether heightened feelings of social connection moderate the deleterious impact of dispositional negativity on momentary 
experience (Disposition $\times$ Connection $\rightarrow$ Experience; path $c$ in Figure 4). As detailed in Table 3, the interaction was significant for all six measures of momentary experience. This result, which reflects assessments of psychological experience (i.e., How accepted, connected, and engaged do you feel?) rather than social context (e.g., Who are you with?), is particularly important because it independently confirms the exaggerated significance of social experience for individuals endowed with a more negative disposition. Furthermore, in these simultaneous MLMs, the Disposition $\times$ Close interaction was no longer significant for four of the outcome measures (negative affect, pessimism, positive affect, and optimism) and was substantially weaker for social avoidance and approach (compare Table 3 to Table 2), underscoring the importance of perceived social connection (Cacioppo et al., 2015; Stokes, 1985) and consistent with the hypothesized moderated mediation model.

As shown in Figure 6 and Table 4, simple effects analyses yielded two additional conclusions. First, the adverse influence of dispositional negativity on momentary experience is reduced (i.e., the regression slope is flatter) in moments when perceived social connection is high (solid green line) relative to when it is low (broken green line). This is particularly evident for negative affect, social avoidance, and pessimism. Second, individuals with a more negative disposition derive larger emotional benefits from perceptions of social connection compared to those with a less negative disposition (i.e., the difference between the solid and broken green lines is magnified at high levels of negativity). These results suggest that the emotional benefits that dispositionally negative individuals derive from the company of close others (Figure 3) and, to a lesser degree distant others, are largely explained by heightened feelings of social engagement and acceptance (Figure 6), rather than some other context-dependent variable (e.g., activity).

\section{Heightened social connection mediates the impact of close companions on momentary experience-Finally, we formally assessed whether the impact of close} companions on momentary emotional experience is statistically mediated by heightened feelings of social connection. Using well-established Monte Carlo techniques (Preacher \& Selig, 2012), we estimated 95\% confidence intervals (CIs) for the indirect effect of connection (i.e., Close Others $\rightarrow$ Connection $\rightarrow$ Experience; gray paths in Figure 4). As detailed in Table 5, the emotional benefits of close companions were significantly mediated by heightened feelings of social connection for all six outcome measures (i.e., the $95 \%$ CIs did not include 0), $p s<.05$. Critically, the $95 \%$ CIs for individuals with high levels of dispositional negativity (upper row of Table 5) were more extreme and did not overlap those for individuals with low levels of dispositional negativity (lower row of Table 5), indicating stronger mediation effects. Taken together, these results indicate that individuals with a more negative disposition derive larger emotional benefits from the company of close companions in their daily lives and that these benefits reflect heightened feelings of social connection (Figure 3b).

\section{Discussion}

Elevated levels of dispositional negativity confer increased risk for a broad spectrum of adverse outcomes, from divorce and mental illness to physical disease and death. The present study provides new insights into how the social environment shapes the momentary 
experience and expression of dispositional negativity in the real world, close to these important end-points. On average, individuals with a more negative disposition experienced substantially higher levels of negative affect, avoidance motivation, and pessimism and lower levels of positive affect, approach motivation, and optimism in their daily lives (Supplementary Tables 2-3), replicating and extending prior experience-sampling work focused on context-independent positive and negative affect. EMA data provide unique evidence that this effect is largely unrelated to the amount of time budgeted to particular social environments ${ }^{4}$. Like many other young adults (Figure 2 ), dispositionally negative individuals spend the majority of their waking hours in the company of others. This suggests that objective social isolation, avoidance, or other kinds of context-selection effects are not core determinants of their momentary emotional experience, at least during this phase of development (Qualter et al., 2015). Instead, our results highlight the key role that close companions-friends, romantic partners, and family members-play in moderating momentary emotional experience (Figure 3 ) and show that this is particularly evident among individuals marked by high levels of dispositional negativity. In fact, these results show that dispositionally negative individuals derive substantially larger emotional benefits-lower levels of negative affect, avoidance motivation, and pessimism and higher levels of positive affect, approach motivation, and optimism - from the company of close companions relative to the company of strangers or acquaintances, to solitary contexts, or to individuals with a less negative disposition (Figure 3). Moreover, the results of our mediation analyses indicated that these enhanced emotional benefits reflect exaggerated feelings of social connection and acceptance in the presence of intimates (Figures 4-5). In short, moment-bymoment fluctuations in perceived social connection play a key role in governing the expression and experience of dispositional negativity in daily life. These results provide a novel framework for understanding the processes that contribute to the development of mental illness and other adverse outcomes linked to dispositional negativity, for guiding the development of improved intervention strategies, and for clarifying the interplay of personality and the environment.

The present observations complement a growing body of laboratory evidence highlighting the importance of social and interpersonal processes for emotion regulation (Coan \& Sbarra, 2015; S. L. Gable, \& Reis, H. T., 2010; Lakey \& Orehek, 2011; Zaki \& Williams, 2013). Our results suggest that individuals with a more negative disposition are particularly dependent on intimate companions for regulating their persistently elevated distress. Indeed, inspection of Figure 3 indicates that the emotional experience of high-negative individuals most closely resembles that of low-negative individuals when they are in the company of their close companions, particularly for positive facets of momentary experience (e.g., optimism about the future). A broadly similar pattern has been observed in several randomized laboratory studies, suggesting that close companions play a causal role in normalizing emotional experience. For example, the presence of a close companion has been shown to normalize negative affect and catastrophic cognitions ('I'm going to die') in panic disorder patients exposed to a panic-inducing $\mathrm{CO}_{2}$ challenge (Carter, Hollon, Carson, \& Shelton, 1995) and to normalize behavioral signs of anxiety in socially anxious young adults during a videotaped speech challenge (Pontari, 2009). More naturalistic research indicates that dispositionally negative individuals are characterized by poor emotion regulation skills 
(Suls \& Martin, 2005) and are prone to coping with stress by seeking the emotional support of intimates (Bolger \& Zuckerman, 1995; Connor-Smith \& Flachsbart, 2007). Observational studies of married couples show that individuals with a more negative disposition solicit and receive more socio-emotional support from their spouses (Pasch, Bradbury, \& Davila, 1997; Wang \& Repetti, 2014) and diary studies of anxiety patients suggest that enhanced spousal support dampens negative affect (Zaider, Heimberg, \& Iida, 2010). Collectively, this body of observations suggests that friends, romantic partners, and family members serve as a regulatory 'prosthesis' for dispositionally negative individuals.

Relying on intimates for emotion regulation is risky. This is particularly true for dispositionally negative individuals, who tend to behave in ways that promote interpersonal conflict, social rejection, and the dissolution of close relationships (Karney \& Bradbury, 1995; Robins et al., 2002). Relationship distress and dissolution reduces or eliminates the possibility of interpersonal emotion regulation and, ultimately, can contribute to the development and maintenance of anxiety disorders, depression, and substance abuse (Baucom, Belus, Adelman, Fischer, \& Paprocki, 2014; Marroquin, 2011; Rehman, Gollan, \& Mortimer, 2008; Whisman \& Baucom, 2012). Even in the absence of relationship problems, as young adults transition to full-time employment, marriage, and parenting, social network size begins to decline and more time is spent alone (Larson, 1990; Wrzus, Hanel, Wagner, \& Neyer, 2013; Wrzus, Wagner, \& Riediger, 2016), particularly among those who are single or widowed (Larson, 1990). Many middle-aged and older adults report that they have no confidant (McPherson \& Smith-Lovin, 2006), depriving them of opportunities for interpersonal emotion regulation. This is likely to be exacerbated among individuals with a more negative disposition, who report fewer confidants by mid-life (Kendler et al., 2003).

From an intervention perspective, these observations suggest that naturally occurring social relationships represent an important target for a range of adverse outcomes, including marital problems, emotional disorders, and stress-sensitive illness (S. Cohen, 2004; Editors, 2010). Existing treatments for extreme dispositional negativity typically focus on the individual (Barlow, Sauer-Zavala, Carl, Bullis, \& Ellard, 2013), but our results highlight the value of simultaneously considering the role of close companions (Baucom et al., 2014) and developing interventions to enhance social connection, acceptance, and support. This could take the form of nurturing social-cognitive skills, cultivating stronger and more frequent ties with existing companions and social networks (e.g., reduce overreliance on a particular intimate), or reducing maladaptive thoughts and behaviors that promote conflict and rejection (Cacioppo et al., 2015; Kok \& Singer, 2017; Masi, Chen, Hawkley, \& Cacioppo, 2011). The development of smart phone-based interventions would provide a scalable and cost-effective alternative to more traditional modalities (e.g., cognitive-behavioral therapy; Eapen \& Peterson, 2015; Hampton, 2012; Kazdin \& Blase, 2011a, 2011b; Kramer et al., 2014; World Health Organization, 2013) and may be especially effective for the sizable number of individuals who are unable or unwilling to use traditional treatments (Mojtabai et al., 2011). Smart phone-based interventions have a number of other potential advantages, including opportunities for personalized treatment, real-time monitoring of treatment outcomes, and increased engagement (Klasnja \& Pratt, 2012). 
Our findings also have implications for theories of temperament and personality.

Dispositional negativity is usually cast as an increased sensitivity to aversive challenges and psychological pathogens (e.g., conflict, punishment, stress, and threat). From this perspective, dispositional negativity represents a diathesis that promotes heightened levels of negative affect, pessimism, and avoidance motivation in the face of trait-relevant challenges (Eysenck, 1967; Gray \& McNaughton, 2000; Kagan, Reznick, \& Snidman, 1988; Spielberger, 1966; Zuckerman, 1976). The present results and other data (e.g., Aldinger et al., 2014; Ching et al., 2014; David et al., 1997; Emmons \& Diener, 1986; S. L. Gable et al., 2000; Howell, Ksendzova, Netingen, Yerahian, \& Iyer, in press; Howell \& Rodzon, 2011; Jacobs et al., 2011; Komulainen et al., 2014; Kuppens et al., 2007; Lay \& Hoppmann, 2014; Leger et al., 2016; Snippe et al., in press; Soto \& John, in press; Tennen et al., 2006; Watson, 1988; Watson \& Clark, 1984; R. E. Wilson et al., in press; Zautra et al., 2005) underscore the need to broaden this perspective to encompass positive affect and positive experiences. First, our results highlight the substantial, but often overlooked influence of dispositional negativity on positive features of momentary experience, including lower levels of positive affect, optimism, and approach motivation (Figure 3). There is abundant evidence that dispositional negativity confers increased risk for the development of mood disorders (Hengartner, Ajdacic-Gross, Wyss, Angst, \& Rossler, 2016; Laceulle, Ormel, Vollebergh, van Aken, \& Nederhof, 2014; Naragon-Gainey \& Watson, 2014; Ormel et al., 2013; Zinbarg et al., 2016) and these moment-by-moment relations may provide an anhedonic pathway for the development of pathological depression. Second, our results make it clear that individuals with a more negative disposition are not just hyper-sensitive to threat, they are also differentially sensitive to the company of intimates and to environments that elicit feelings of connection, acceptance, and intimacy (Figure 5). Our observations may also provide insights into the mechanisms underlying long-term changes in dispositional negativity. Like other core emotional traits, dispositional negativity is somewhat malleable and continues to evolve across the lifespan (Fraley \& Roberts, 2005; B. W. Roberts \& DelVecchio, 2000; B. W. Roberts et al., 2017; B. W. Roberts \& Mroczek, 2008; B. W. Roberts, Walton, \& Viechtbauer, 2006). Longitudinal studies demonstrate that changes in the social environment (e.g., death of a spouse, re-marriage following widowhood, or gradual shifts in marital satisfaction) are associated with long-lasting changes in dispositional negativity (Mroczek \& Spiro, 2003; B. W. Roberts \& Chapman, 2000; Scollon \& Diener, 2006), but the proximal mechanisms have remained unclear. The present results motivate the hypothesis that these changes in emotional disposition reflect the cumulative impact of longterm alterations in the social regulation of momentary experience.

Our results highlight some other valuable avenues for future research. In particular, the present study provides scant information about the social networks in which dispositionally negative individuals are embedded. For example, we do not know whether more negative individuals rely on many or few close companions. Another key challenge is to discover the specific interactional processes that underlie heightened feelings of social connection and acceptance (Caspi et al., 2005). Observational and experimental studies of dyadic interactions would be particularly valuable for identifying mechanistically important social processes and these could be combined with EMA procedures to establish their relevance to 
real-world experience. Intervention studies would afford a crucial opportunity to test whether the relations that we have identified are causally important.

In sum, the present study suggests that intimate companions play a vital role in governing the momentary expression and experience of dispositional negativity in the real world. Our results indicate that individuals with a more negative disposition derive enhanced emotional benefits from close companions and that these benefits reflect heightened feelings of social connection. The results set the stage for developing improved strategies for treating or even preventing the deleterious consequences of extreme dispositional negativity. More broadly, they provide new insights into the ways in which traits and situations interactively regulate momentary emotional states.

\section{Supplementary Material}

Refer to Web version on PubMed Central for supplementary material.

\section{Acknowledgments}

Authors acknowledge the assistance of D. Ansah, L. Bjorkman, K. DeYoung, A. Dizik, L. Friedman, A. Heller, J. Kang, J. Kau, E. Qi, J. Smith, M. Sood, and M. Stockbridge. This work was supported by the University of California, University of Maryland, and National Institutes of Health (DA040717 and MH107444).

\section{References}

Affleck G, Tennen H, Urrows S, Higgins P. Person and contextual features of daily stress reactivity: individual differences in relations of undesirable daily events with mood disturbance and chronic pain intensity. Journal of Personality and Social Psychology. 1994; 66:329-340. [PubMed: 8195989]

Aldinger M, Stopsack M, Ulrich I, Appel K, Reinelt E, Wolff S, Barnow S. Neuroticism developmental courses--implications for depression, anxiety and everyday emotional experience; a prospective study from adolescence to young adulthood. BMC Psychiatry. 2014; 14

Alloy LB, Abramson LY. The Temple-Wisconsin Cognitive Vulnerability to Depression Project: Conceptual background, design, and methods. Journal of Cognitive Psychotherapy. 1999; 13:227_ 262.

American College Health AssociationAmerican College Health Association-National College Health Assessment II: Reference Group Executive Summary Fall 2015Hanover, MD: American College Health Association; 2016

Arnett JJ. Emerging adulthood. A theory of development from the late teens through the twenties. American Psychologist. 2000; 55:469-480. [PubMed: 10842426]

Asendorpf JB, Wilpers S. Personality effects on social relationships. Journal of Personality \& Social Psychology. 1998; 74:1531-1544.

Barlow DH, Sauer-Zavala S, Carl JR, Bullis JR, Ellard KK. The nature, diagnosis, and treatment of neuroticism: Back to the future. Clinical Psychological Science. 2013; 2

Barrett LF. The relationships among momentary emotion experiences, personality descriptions, and retrospective ratings of emotion. Personality and Social Psychology Bulletin. 1997; 10:1100-1110.

Baucom DH, Belus JM, Adelman CB, Fischer MS, Paprocki C. Couple-based interventions for psychopathology: a renewed direction for the field. Family Process. 2014; 53:445-461. [PubMed: 24773298]

Beesdo K, Pine DS, Lieb R, Wittchen HU. Incidence and risk patterns of anxiety and depressive disorders and categorization of generalized anxiety disorder. Archives of General Psychiatry. 2010; 67:47-57. [PubMed: 20048222] 
Berry DS, Hansen JS. Positive affect, negative affect, and social interaction. Journal of Personality and Social Psychology. 1996; 71:796-809.

Berry DS, Willingham JK, Thayer CA. Affect and personality as predictors of conflict and closeness in young adults' friendships. Journal of Research in Personality. 2000; 34:84-107.

Bolger N, Delongis A, Kessler RC, Wethington E. The contagion of stress across multiple roles. Journal of Marriage and the Family. 1989; 51:175-183.

Bolger N, Eckenrode J. Social relationships, personality, and anxiety during a major stressful event. Journal of Personality and Social Psychology. 1991; 61:440-449. [PubMed: 1941515]

Bolger N, Schilling EA. Personality and the problems of everyday life: the role of neuroticism in exposure and reactivity to daily stressors. Journal of Personality. 1991; 59:355-386. [PubMed: 1960637]

Bolger N, Zuckerman A. A framework for studying personality in the stress process. Journal of Personality and Social Psychology. 1995; 69:890-902. [PubMed: 7473036]

Brewer BW, Cornelius AE, Sklar JH, Van Raalte JL, Tennen H, Armeli S, Brickner JC. Pain and negative mood during rehabilitation after anterior cruciate ligament reconstruction: a daily process analysis. Scandinavian Journal of Medicine and Science in Sports. 2007; 17:520-529. [PubMed: 17076828]

Brock RL, Dindo L, Simms LJ, Clark LA. Personality and dyadic adjustment: Who you think your partner is really matters. J Fam Psychol. 2016; 30:602-613. [PubMed: 27100564]

Brown LH, Strauman T, Barrantes-Vidal N, Silvia PJ, Kwapil TR. An experience-sampling study of depressive symptoms and their social context. Journal of Nervous and Mental Disease. 2011; 199:403-409. [PubMed: 21629020]

Buote VM, Pancer SM, Pratt MW, Adams G, Birnie-Lefcovitch S, Polivy J, Wintre MG. The importance of friends. Friendship and adjustment among 1st-year university students. Journal of Adolescent Research. 2007; 22:665-689.

Buss DM. Conflict in married couples: Personality predictors of anger and upset. Journal of Personality. 1991; 59:663-703. [PubMed: 1774615]

Cacioppo S, Grippo AJ, London S, Goossens L, Cacioppo JT. Loneliness: clinical import and interventions. Perspect Psychol Sci. 2015; 10:238-249. [PubMed: 25866548]

Carstensen LL, Pasupathi M, Mayr U, Nesselroade JR. Emotional experience in everyday life across the adult life span. Journal of Personality and Social Psychology. 2000; 79:644-655. [PubMed: 11045744]

Carter MM, Hollon SD, Carson RE, Shelton RC. Effects of a safe person on induced distress following a biological challenge in panic disorder with agoraphobia. Journal of Abnormal Psychology. 1995; 104:156-163. [PubMed: 7897039]

Caspi A, Roberts BW, Shiner RL. Personality development: stability and change. Annual Review of Psychology. 2005; 56:453-484.

Chapman BP, Fiscella K, Kawachi I, Duberstein PR. Personality, socioeconomic status, and all-cause mortality in the United States. American Journal of Epidemiology. 2010; 171:83-92. [PubMed: 19965888]

Ching CM, Church AT, Katigbak MS, Reyes JAS, Tanaka-Matsumi J, Takaoka S, Ortiz FA. The manifestation of traits in everyday behavior and affect: A five-culture study. Journal of Research in Personality. 2014; 48:1-16.

Clark LA, Watson D. Mood and the mundane: Relations between daily life events and self-reported mood. Journal of Personality and Social Psychology. 1988a; 54:296-308. [PubMed: 3346815]

Clark LA, Watson D. Mood and the mundane: relations between daily life events and self-reported mood. Journal of Personality and Social Psychology. 1988b; 54:296-308. [PubMed: 3346815]

ClarkMS, , LemayEP, Jr. Close relationships. In: FiskeST, GilbertDT, , LindzeyG, editorsHandbook of Social Psychology5th. Vol. 2. NY: Wiley; 2010898940

Coan JA, Sbarra DA. Social baseline theory: The social regulation of risk and effort. Curr Opin Psychol. 2015; 1:87-91. [PubMed: 25825706]

CohenJ, , CohenP, , WestSG, , AikenLS. Applied multiple regression/correlation analysis for the behavioral sciences3rd. Mahwah, NJ: LEA; 2003 
Cohen S. Social relationships and health. American Psychologist. 2004; 59:676-684. [PubMed: 15554821]

Connor-Smith JK, Flachsbart C. Relations between personality and coping: a meta-analysis. Journal of Personality and Social Psychology. 2007; 93:1080-1107. [PubMed: 18072856]

CottrellNB, , EpleySW. Affiliation, social comparison, and socially mediated stress reduction. In: SulsJM, , MillerRL, editorsSocial comparison processes: Theoretical and empirical perspectivesWashington, DC: Hemisphere; 19774368

Creed AT, Funder DC. Social anxiety: from the inside and outside. Personality and Individual Differences. 1998; 25:19-33.

Csikszentmihalyi M, Hunter JE. Happiness in everyday life: The uses of experience sampling. Journal of Happiness Studies. 2003; 4:185-199.

Cuijpers P, Smit F, Penninx BW, de Graaf R, ten Have M, Beekman AT. Economic costs of neuroticism: a population-based study. Archives of General Psychiatry. 2010; 67:1086-1093. [PubMed: 20921124]

Damian RI, Su R, Shanahan M, Trautwein U, Roberts BW. Can personality traits and intelligence compensate for background disadvantage? Predicting status attainment in adulthood. Journal of Personality and Social Psychology. 2015; 109:473-489. [PubMed: 25402679]

David JP, Green PJ, Martin R, Suls J. Differential roles of neuroticism, extraversion, and event desirability for mood in daily life: an integrative model of top-down and bottom-up influences. Journal of Personality and Social Psychology. 1997; 73:149-159. [PubMed: 9216082]

Donnellan MB, Larsen-Rife D, Conger RD. Personality, family history, and competence in early adult romantic relationships. Journal of Personality and Social Psychology. 2005; 88:562-576. [PubMed: 15740446]

Dyrenforth PS, Kashy DA, Donnellan MB, Lucas RE. Predicting relationship and life satisfaction from personality in nationally representative samples from three countries: The relative importance of actor, partner, and similarity effects. Journal of Personality and Social Psychology. 2010; 99:690702. [PubMed: 20718544]

Eapen ZJ, Peterson ED. Can mobile health applications facilitate meaningful behavioral change? Time for answers. JAMA. 2015; 314:1237-1237.

Eddington KM, Majestic C, Silvia PJ. Contrasting regulatory focus and reinforcement sensitivity: A daily diary study of goal pursuit and emotion. Personality and Individual Differences. 2012; 53:335-340. [PubMed: 22736878]

Editors TPM. Social relationships are key to health, and to health policy. PLoS Med. 2010; 7:2.

Emmons RA, Diener E. Influence of impulsivity and sociability on subjective well-being. Journal of Personality and Social Psychology. 1986; 50:1211-1215.

EysenckHJ. The biological basis of personalitySpringfield, IL: Charles C. Thomas; 1967

Fava M, Hwang I, Rush AJ, Sampson N, Walters EE, Kessler RC. The importance of irritability as a symptom of major depressive disorder: results from the National Comorbidity Survey Replication. Molecular Psychiatry. 2010; 15:856-867. [PubMed: 19274052]

Fraley RC, Roberts BW. Patterns of continuity: a dynamic model for conceptualizing the stability of individual differences in psychological constructs across the life course. Psychological Review. 2005; 112:60-74. [PubMed: 15631588]

Gable SL, Reis HT. Good news! Capitalizing on positive events in an interpersonal context. Advances in Experimental Social Psychology. 2010; 42:195-257.

Gable SL, Reis HT, Elliot AJ. Behavioral activation and inhibition in everyday life. Journal of Personality and Social Psychology. 2000; 78:1135-1149. [PubMed: 10870914]

Gale CR, Hagenaars SP, Davies G, Hill WD, Liewald DC, Cullen B, Harris SE. Pleiotropy between neuroticism and physical and mental health: findings from 108038 men and women in UK Biobank. Transl Psychiatry. 2016; 6:e791. [PubMed: 27115122]

GoldbergLR. A broad-bandwidth, public domain, personality inventory measuring the lower-level facets of several five-factor models. In: MervieldeI, DearyI, De FruytF, , OstendorfF, editorsPersonality Psychology in EuropeVol. 7. Tilburg, The Netherlands: Tilburg University Press; 1999728 
Goldberg LR, Johnson JA, Eber HW, Hogan R, Ashton MC, Cloninger CR, Gough HC. The International Personality Item Pool and the future of public-domain personality measures. Journal of Research in Personality. 2006; 40:84-96.

Goodwin RD, Hoven CW, Lyons JS, Stein MB. Mental health service utilization in the United States. The role of personality factors. Social Psychiatry and Psychiatric Epidemiology. 2002; 37:561566. [PubMed: 12545232]

Granovetter MS. The strength of weak ties. American Journal of Sociology. 1973; 78:1360-1380.

GrayJA, , McNaughtonN. The neuropsychology of anxiety2nd. NY: Oxford University Press; 2000

GrossJJ, , RichardsJM, , JohnOP. Emotion regulation in everyday life. In: SnyderDK, SimpsonJA, , HughesJN, editorsEmotion regulation in families: Pathways to dysfunction and healthWashington, DC: American Psychological Association; 2006

Gunaydin G, Selcuk E, Ong AD. Trait reappraisal predicts affective reactivity to daily positive and negative events. Front Psychol. 2016; 7:1000. [PubMed: 27445954]

Hakulinen C, Elovainio M, Pulkki-Raback L, Virtanen M, Kivimaki M, Jokela M. Personality and depressive symptoms: Individual participant meta-analysis of 10 cohort studies. Depression and Anxiety. 2015; 32:461-470. [PubMed: 26014798]

Hakulinen C, Hintsanen M, Munafo MR, Virtanen M, Kivimaki M, Batty GD, Jokela M. Personality and smoking: individual-participant meta-analysis of nine cohort studies. Addiction. 2015; 110:1844-1852. [PubMed: 26227786]

Hampton T. Recent advances in mobile technology benefit global health, research, and care. JAMA. 2012; 307:2013-2014. [PubMed: 22665083]

Hankin BL, Fraley RC, Abela JR. Daily depression and cognitions about stress: evidence for a traitlike depressogenic cognitive style and the prediction of depressive symptoms in a prospective daily diary study. Journal of Personality and Social Psychology. 2005; 88:673-685. [PubMed: 15796667]

HayesAF. Introduction to mediation, moderation, and conditional process analysis: A regression-based approachNY: Guilford; 2013

Hays RB, Oxley D. Social network development and functioning during a life transition. Journal of Personality and Social Psychology. 1986; 50:305-313. [PubMed: 3701579]

Heiy JE, Cheavens JS. Back to basics: a naturalistic assessment of the experience and regulation of emotion. Emotion. 2014; 14:878-891. [PubMed: 24999913]

Hengartner MP, Ajdacic-Gross V, Wyss C, Angst J, Rossler W. Relationship between personality and psychopathology in a longitudinal community study: a test of the predisposition model. Psychological Medicine. 2016; 46:1693-1705. [PubMed: 26979285]

Hepburn L, Eysenck MW. Personality, average mood, and mood variability. Personality and Individual Differences. 1989; 10:975-983.

Hofmann W, Patel PV. SurveySignal. A convenient solution for experience sampling research using participants' own smartphones. Social Science Computer Review. 2015; 33:235-253.

Howell RT, Ksendzova M, Netingen E, Yerahian C, Iyer R. Your personality on a good day: How trait and state personality predict daily well-being. Journal of Research in Personality. (in press).

Howell RT, Rodzon KS. An exploration of personality-affect relations in daily life: Determiningthe support for the affect-level and affect-reactivity views. Personality and Individual Differences. 2011; 51:797-801.

Howland M, Armeli S, Feinn R, Tennen H. Daily emotional stress reactivity in emerging adulthood: temporal stability and its predictors. Anxiety Stress Coping. 2017; 30:121-132. [PubMed: 27635675]

Hutteman R, Bleidorn W, Kereste G, Brkovic I, Butkovic A, Denissen JJA. Reciprocal associations between parenting challenges and parents' personality development in young and middle adulthood. European Journal of Personality. 2014; 28:168-179.

Jacobs N, van Os J, Derom C, Thiery E, Delespaul P, Wichers M. Neuroticism explained? From a noninformative vulnerability marker to informative person-context interactions in the realm of daily life. British Journal of Clinical Psychology. 2011; 50:19-32. [PubMed: 21332518] 
Jensen-Campbell LA, Adams RB Jr, Perry DG, Workman KA, Furdella JQ, Egan SK. Agreeableness, extraversion, and peer relations in early adolescence: Winning friends and deflecting aggression. Journal of Research in Personality. 2002; 36:224-251.

Jeronimus BF, Kotov R, Riese H, Ormel J. Neuroticism's prospective association with mental disorders halves after adjustment for baseline symptoms and psychiatric history, but the adjusted association hardly decays with time: a meta-analysis on 59 longitudinal/prospective studies with 443313 participants. Psychological Medicine. 2016; 46(14):2883-2906. [PubMed: 27523506]

JohnOP, , NaumannLP, , SotoCJ. Paradigm shift to the integrative big-five trait taxonomy: History, measurement, and conceptual issues. In: JohnOP, RobinsRW, , PervinLA, editorsHandbook of personality: Theory and researchNY: Guilford; 2008114158

Judge TA, Erez A, Bono JE, Thoresen CJ. Are measures of self-esteem, neuroticism, locus of control, and generalized self-efficacy indicators of a common core construct? Journal of Personality and Social Psychology. 2002; 83:693-710. [PubMed: 12219863]

Kagan J, Reznick JS, Snidman N. Biological bases of childhood shyness. Science. 1988; 240:167-171. [PubMed: 3353713]

Kahneman D, Krueger AB, Schkade DA, Schwarz N, Stone AA. A survey method for characterizing daily life experience: the day reconstruction method. Science. 2004; 306:1776-1780. [PubMed: 15576620]

Kardum I. Affect intensity and frequency their relation to mean level and variability of positive and negative a ect and Eysenck's personality traits. Personality and Individual Differences. 1999; 26:33-47.

Karney BR, Bradbury TN. The longitudinal course of marital quality and stability: a review of theory, method, and research. Psychological Bulletin. 1995; 118:3-34. [PubMed: 7644604]

Kazdin AE, Blase SL. Interventions and models of their delivery to reduce the burden of mental illness: Reply to commentaries. Perspect Psychol Sci. 2011a; 6:507-510. [PubMed: 26168204]

Kazdin AE, Blase SL. Rebooting psychotherapy research and practice to reduce the burden of mental illness. Perspect Psychol Sci. 2011b; 6:21-37. [PubMed: 26162113]

Kendler KS, Gardner CO, Prescott CA. Personality and the experience of environmental adversity. Psychological Medicine. 2003; 33:1193-1202. [PubMed: 14580074]

Kessler RC, Berglund PA, Demler O, Jin R, Merikangas KR, Walters EE. Lifetime prevalence and ageof-onset distributions of DSM-IV disorders in the National Comorbidity Survey Replication (NCSR). Archives of General Psychiatry. 2005; 62:593-602. [PubMed: 15939837]

Klasnja P, Pratt W. Healthcare in the pocket: mapping the space of mobile-phone health interventions. Journal of Biomedical Informatics. 2012; 45:184-198. [PubMed: 21925288]

Kok BE, Singer T. Effects of contemplative dyads on engagement and perceived social connectedness over 9 months of mental training: A randomized clinical trial. JAMA Psychiatry. 2017; 74:126134. [PubMed: 28030741]

Komulainen E, Meskanen K, Lipsanen J, Lahti JM, Jylha P, Melartin T, Ekelund J. The effect of personality on daily life emotional processes. PLoS ONE. 2014; 9:e110907. [PubMed: 25343494]

Kotov R, Gamez W, Schmidt F, Watson D. Linking "big” personality traits to anxiety, depressive, and substance use disorders: a meta-analysis. Psychological Bulletin. 2010; 136:768-821. [PubMed: 20804236]

Kramer I, Simons CJ, Hartmann JA, Menne-Lothmann C, Viechtbauer W, Peeters F, Wichers M. A therapeutic application of the experience sampling method in the treatment of depression: a randomized controlled trial. World Psychiatry. 2014; 13(1):68-77. [PubMed: 24497255]

KruegerAB, , KahnemanD, , SchkadeD, , SchwartzN, , StoneAA. National time accounting. The currency of life. In: KruegerAB, editorMeasuring the subjective well-being of nations: National accounts of time use and well-beingChicago: University of Chicago Press; 2009986

Kuppens P, Oravecz Z, Tuerlinckx F. Feelings change: accounting for individual differences in the temporal dynamics of affect. Journal of Personality and Social Psychology. 2010; 99:1042-1060. [PubMed: 20853980]

Kuppens P, Van Mechelen I, Nezlek JB, Dossche D, Timmermans T. Individual differences in core affect variability and their relationship to personality and psychological adjustment. Emotion. 2007; 7:262-274. [PubMed: 17516805] 
Laceulle OM, Ormel J, Vollebergh WA, van Aken MA, Nederhof E. A test of the vulnerability model: temperament and temperament change as predictors of future mental disorders - the TRAILS study. Journal of Child Psychology and Psychiatry and Allied Disciplines. 2014; 55:227-236.

Lakey B, Orehek E. Relational regulation theory: a new approach to explain the link between perceived social support and mental health. Psychological Review. 2011; 118:482-495. [PubMed: 21534704]

Larson RW. The solitary side of life: An examination of the time people spend alone from childhood to old age. Developmental Review. 1990; 1990(10)

Lay JC, Gerstorf D, Scott SB, Pauly T, Hoppmann CA. Neuroticism and extraversion magnify discrepancies between retrospective and concurrent affect reports. Journal of Personality. (in press).

Lay JC, Hoppmann CA. Spousal neuroticism moderates everyday problem--wellbeing associations in older couples. Health Psychology. 2014; 33:803-812. [PubMed: 24707846]

Leger KA, Charles ST, Turiano NA, Almeida DM. Personality and stressor-related affect. Journal of Personality and Social Psychology. 2016; 111:917-928. [PubMed: 26796984]

Mahaffey BL, Watson D, Clark LA, Kotov R. Clinical and personality traits in emotional disorders: Evidence of a common framework. Journal of Abnormal Psychology. 2016; 125:758-767. [PubMed: 27505406]

Marco CA, Suls J. Daily stress and the trajectory of mood: spillover, response assimilation, contrast, and chronic negative affectivity. Journal of Personality and Social Psychology. 1993; 64:10531063. [PubMed: 8326468]

Marroquin B. Interpersonal emotion regulation as a mechanism of social support in depression. Clinical Psychology Review. 2011; 31:1276-1290. [PubMed: 21983267]

Masi CM, Chen HY, Hawkley LC, Cacioppo JT. A meta-analysis of interventions to reduce loneliness. Pers Soc Psychol Rev. 2011; 15:219-266. [PubMed: 20716644]

McConville C, Cooper C. Personality correlates of variable moods. Personality and Individual Differences. 1999; 26:65-78.

McPherson M, Smith-Lovin L. Social isolation in America: Changes in core discussion networks over two decades. American Sociological Review. 2006; 71:353-375.

Mehl MR, Gosling SD, Pennebaker JW. Personality in its natural habitat: manifestations and implicit folk theories of personality in daily life. Journal of Personality and Social Psychology. 2006; 90:862-877. [PubMed: 16737378]

Mojtabai R, Olfson M, Sampson NA, Jin R, Druss B, Wang PS, Kessler RC. Barriers to mental health treatment: results from the National Comorbidity Survey Replication. Psychological Medicine. 2011; 41:1751-1761. [PubMed: 21134315]

Molho C, Roberts SGB, de Vries RE, Pollet TV. The six dimensions of personality (HEXACO) and their associations with network layer size and emotional closeness to network members. Personality and Individual Differences. 2016; 99:144-148.

Mroczek DK, Almeida DM. The effect of daily stress, personality, and age on daily negative affect. Journal of Personality. 2004; 72:355-378. [PubMed: 15016068]

Mroczek DK, Spiro A 3rd. Modeling intraindividual change in personality traits: findings from the normative aging study. Journals of Gerontology Series B, Psychological Sciences and Social Sciences. 2003; 58:153-165.

Mund M, Neyer FJ. The winding paths of the lonesome cowboy: Evidence for mutual influences between personality, subjective health, and loneliness. J Personality. 2016; 84:646-657. [PubMed: 26112403]

MyersDG. Close relationships and quality of life. In: KahnemanD, DienerE, , SchwartzN, editorsWellbeingNY: Sage; 1999374391

Naragon-Gainey K, Watson D. Consensually defined facets of personality as prospective predictors of change in depression symptoms. Assessment. 2014; 21:387-403. [PubMed: 24671734]

$\mathrm{Ng}$ TWH, Eby LT, Sorensen KL, Feldman DC. Predictors of objective and subjective career success. A meta-analysis. Personnel Psychology. 2005; 58:367-408. 
O'Hara RE, Armeli S, Boynton MH, Tennen H. Emotional stress-reactivity and positive affect among college students: the role of depression history. Emotion. 2014; 14:193-202. [PubMed: 24274764]

Ode S, Hilmert CJ, Zielke DJ, Robinson MD. Neuroticism's importance in understanding the daily life correlates of heart rate variability. Emotion. 2010; 10:536-543. [PubMed: 20677870]

Ong AD, Zautra AJ, Reid MC. Psychological resilience predicts decreases in pain catastrophizing through positive emotions. Psychology and Aging. 2010; 25:516-523. [PubMed: 20853962]

Ormel J, Jeronimus BF, Kotov R, Riese H, Bos EH, Hankin B, Oldehinkel AJ. Neuroticism and common mental disorders: meaning and utility of a complex relationship. Clinical Psychology Review. 2013; 33:686-697. [PubMed: 23702592]

Palmier-Claus JE, Myin-Germeys I, Barkus E, Bentley L, Udachina A, Delespaul PA, Dunn G. Experience sampling research in individuals with mental illness: reflections and guidance. Acta Psychiatrica Scandinavica. 2011; 123(1):12-20. [PubMed: 20712828]

Park CL, Armeli S, Tennen H. Appraisal-coping goodness of fit: A daily internet study. Personality and Social Psychology Bulletin. 2004; 30:558-569. [PubMed: 15107156]

Pasch LA, Bradbury TN, Davila J. Gender, negative affectivity, and observed social support behavior in marital interaction. Personal Relationships. 1997; 4:361-378.

Pontari BA. Appearing socially competent: The effects of a friend's presence on the socially anxious. Personality and Social Psychology Bulletin. 2009; 35:283-294. [PubMed: 19223456]

Preacher KJ, Selig JP. Advantages of Monte Carlo confidence intervals for indirect effects. Communication Methods and Measures. 2012; 6:77-98.

Pressman SD, Cohen S, Miller GE, Barkin A, Rabin BS, Treanor JJ. Loneliness, social network size, and immune response to influenza vaccination in college freshmen. Health Psychology. 2005; 24:297-306. [PubMed: 15898866]

Qualter P, Vanhalst J, Harris R, Van Roekel E, Lodder G, Bangee M, Verhagen M. Loneliness across the life span. Perspect Psychol Sci. 2015; 10:250-264. [PubMed: 25910393]

Rehman US, Gollan J, Mortimer AR. The marital context of depression: research, limitations, and new directions. Clinical Psychology Review. 2008; 28:179-198. [PubMed: 17573169]

ReisHT, , ShaverPR. Intimacy as an interpersonal process. In: DuckSW, editorHandbook of personal relationshipsNY: Wiley; 1989367389

Reis HT, Sheldon KM, Gable SL, Roscoe J, Ryan RM. Daily well-being: The role of autonomy, competence, and relatedness. Personality and Social Psychology Bulletin. 2000; 26:419-435.

Rime B. Emotion elicits the social sharing of emotion: Theory and empirical review. Emotion Review. 2009; $1: 60-85$.

Roberts BW, Chapman CN. Change in dispositional well-being and its relation to role quality: A 30year longitudinal study. Journal of Research in Personality. 2000; 34:26-41.

Roberts BW, DelVecchio WF. The rank-order consistency of personality traits from childhood to old age: a quantitative review of longitudinal studies. Psychological Bulletin. 2000; 126:3-25. [PubMed: 10668348]

Roberts BW, Luo J, Briley DA, Chow PI, Su R, Hill PL. A systematic review of personality trait change through intervention. Psychological Bulletin. 2017; 143:117-141. [PubMed: 28054797]

Roberts BW, Mroczek D. Personality trait change in adulthood. Curr Dir Psychol Sci. 2008; 17:31-35. [PubMed: 19756219]

Roberts BW, Walton KE, Viechtbauer W. Patterns of mean-level change in personality traits across the life course: a meta-analysis of longitudinal studies. Psychological Bulletin. 2006; 132:1-25. [PubMed: 16435954]

Roberts SGB, Wilson RE, Fedurek P, Dunbar RIM. Individual differences and personal social network size and structure. Personality and Individual Differences. 2008; 44:954-964.

Robins RW, Caspi A, Moffitt TE. It's not just who you're with, it's who you are: Personality and relationship experiences across multiple relationships. Journal of Personality. 2002; 70:925-964. [PubMed: 12498360] 
Rodell JB, Judge TA. Can "good" stressors spark "bad" behaviors? The mediating role of emotions in links of challenge and hindrance stressors with citizenship and counterproductive behaviors. Journal of Applied Psychology. 2009; 94:1438-1451. [PubMed: 19916654]

Rusting CL, Larsen RJ. Diurnal patterns of unpleasant mood: Associations with neuroticism, depression, and anxiety. Journal of Personality. 1998; 66:85-103. [PubMed: 9457771]

Schimmack U. Affect measurement in experience sampling research. Journal of Happiness Studies. 2003; 4:79-106.

Scollon CN, Diener E. Love, work, and changes in extraversion and neuroticism over time. Journal of Personality and Social Psychology. 2006; 91:1152-1165. [PubMed: 17144771]

Selfhout M, Burk W, Branje S, Denissen J, van Aken M, Meeus W. Emerging late adolescent friendship networks and Big Five personality traits: a social network approach. Journal of Personality. 2010; 78:509-538. [PubMed: 20433629]

Shackman AJ, Kaplan CM, Stockbridge MD, Tillman RM, Tromp DPM, Fox AS, Gamer M. The neurobiology of anxiety and attentional biases to threat: Implications for understanding anxiety disorders in adults and youth. Journal of Experimental Psychopathology. 2016; 7:311-342. [PubMed: 27917284]

Shackman AJ, Tromp DPM, Stockbridge MD, Kaplan CM, Tillman RM, Fox AS. Dispositional negativity: An integrative psychological and neurobiological perspective. Psychological Bulletin. 2016; 142:1275-1314. [PubMed: 27732016]

Shanahan MJ, Bauldry S, Roberts BW, Macmillan R, Russo R. Personality and the reproduction of social class. Social Forces. 2014; 93:209-240.

Sherry SB, Hall PA. The perfectionism model of binge eating: Tests of an integrative model. Journal of Personality and Social Psychology. 2009; 96:690-709. [PubMed: 19254113]

Skalina LM, Gunthert KC, Ahrens AH, Wenze SJ. Neuroticism and momentary differentiation of positive and negative affect. Personality and Individual Differences. 2015; 75:165-169.

Slatcher RB, Vazire S. Effects of global and contextualized personality on relationship satisfaction. Journal of Research in Personality. 2009; 43:624-633.

Snippe E, Jeronimus BF, Aan Het Rot M, Boszormenyi E, de Jonge P, Wichers M. The reciprocity of prosocial behavior and positive affect in daily life. Journal of Personality. (in press).

Soto CJ, John OP. Traits in transition: the structure of parent-reported personality traits from early childhood to early adulthood. Journal of Personality. 2014; 82:182-199. [PubMed: 23734942]

Soto CJ, John OP. The next Big Five Inventory (BFI-2): Developing and assessing a hierarchical model with 15 Facets to enhance bandwidth, fidelity, and predictive power. Journal of Personality and Social Psychology. (in press).

SpielbergerCD. Theory and research on anxiety. In: SpielbergerCD, editorAnxiety and behaviorNY: Academic Press; 1966322

Stanton K, Rozek DC, Stasik SM, Ellickson-Larew S, Watson D. A transdiagnostic approach to examining the incremental predictive power of emotion regulation and basic personality dimensions. Journal of Abnormal Psychology. 2016; 125:960-975. [PubMed: 27732026]

Steel P, Schmidt J, Shultz J. Refining the relationship between personality and subjective well-being. Psychological Bulletin. 2008; 134:138-161. [PubMed: 18193998]

Stokes JJ. The relation of social network and individual difference variables to loneliness. Journal of Personality and Social Psychology. 1985; 48:981-990.

StoneAA, , ShiffmanS, , AtienzaAA, , NebelingL. The science of real-time data captureNU: Oxford University Press; 2007

Suls J, Martin R. The daily life of the garden-variety neurotic: Reactivity, stressor exposure, mood spillover, and maladaptive coping. Journal of Personality. 2005; 73:1485-1509. [PubMed: 16274443]

Suls J, Martin R, David JP. Person-environment fit and its limits: Agreeableness, neuroticism, and emotional reactivity to interpersonal conflict. Personality and Social Psychology Bulletin. 1998; 24:88-98.

Swickert RJ, Hittner JB, Foster A. Big Five traits interact to predict perceived social support. Personality and Individual Differences. 2010; 48:736-741. 
ten Have M, Oldehinkel A, Vollebergh W, Ormel J. Does neuroticism explain variations in care service use for mental health problems in the general population? Results from the Netherlands Mental Health Survey and Incidence Study (NEMESIS). Social Psychiatry and Psychiatric Epidemiology. 2005; 40:425-431. [PubMed: 16003591]

Tennen H, Affleck G, Zautra A. Depression history and coping with chronic pain: a daily process analysis. Health Psychology. 2006; 25:370-379. [PubMed: 16719609]

Terracciano A, Lockenhoff CE, Zonderman AB, Ferrucci L, Costa PT Jr. Personality predictors of longevity: activity, emotional stability, and conscientiousness. Psychosomatic Medicine. 2008; 70:621-627. [PubMed: 18596250]

Tong EMW, Bishop GD, Enkelmann HC, Why YP, Diong SM, Ang J, Khader M. The role of the Big Five in appraisals. Personality and Individual Differences. 2006; 41:512-523.

Totterdell P, Holman D, Hukin A. Social networkers: Measuring and examining individual differences in propensity to connect with others. Social Networks. 2008; 30:283-296.

Verduyn P, Brans B. The relationship between extraversion, neuroticism, and aspects of trait affect. Personality and Individual Differences. 2012; 52:664-669.

Vukasovic T, Bratko D. Heritability of personality: A meta-analysis of behavior genetic studies. Psychological Bulletin. 2015; 141:769-785. [PubMed: 25961374]

Wagner J, Ludtke O, Roberts BW, Trautwein U. Who belongs to me? Social relationship and personality characteristics in the transition to young adulthood. European Journal of Personality. 2014; 28:586-603.

Wang SW, Repetti RL. Psychological well-being and job stress predict marital support interactions: A naturalistic observational study of dual-earner couples in their homes. Journal of Personality and Social Psychology. 2014; 107:864-878. [PubMed: 25347130]

Watson D. Intraindividual and interindividual analyses of positive and negative affect: their relation to health complaints, perceived stress, and daily activities. Journal of Personality and Social Psychology. 1988; 54:1020-1030. [PubMed: 3397861]

Watson D, Clark LA. Negative affectivity: the disposition to experience aversive emotional states. Psychological Bulletin. 1984; 96:465-490. [PubMed: 6393179]

Watson D, Clark LA, McIntyre CW, Hamaker S. Affect, personality, and social activity. Journal of Personality and Social Psychology. 1992; 63:1011-1025. [PubMed: 1460554]

Watson D, Stanton K, Clark LA. Self-report indicators of negative valence constructs within the research domain criteria (RDoC): A critical review. Journal of Affective Disorders. (in press).

Weinstein SM, Mermelstein R. Relations between daily activities and adolescent mood: the role of autonomy. Journal of Clinical Child and Adolescent Psychology. 2007; 36:182-194. [PubMed: 17484691]

Weltz SM, Armelia S, Ford JD, Tennen H. A daily process examination of the relationship between childhood trauma and stress-reactivity. Child Abuse \& Neglect. 2016; 60:1-9. [PubMed: 27639134]

Weston SJ, Hill PL, Jackson JJ. Personality traits predict the onset of disease. Social Psychological and Personality Science. 2015; 6:309-317.

Whisman MA, Baucom DH. Intimate relationships and psychopathology. Clinical Child and Family Psychology Review. 2012; 15:4-13. [PubMed: 22124792]

Williams DG. Persaonlity and mood: State-trait relationships. Personality and Individual Differences. 1981; 2:303-309.

Williams DG. Effects of psychoticism, extraversion, and neuroticism in current mood: A statistical review of six studies. Personality and Individual Differences. 1990; 11:615-630.

Wilson RE, Harris KM, Vazire S. Personality and friendship satisfaction in daily life: Do everyday social interactions account for individual differences in friendship satisfaction. European Journal of Personality. 2015; 29:173-186.

Wilson RE, Thompson RJ, Vazire S. Are fluctuations in personality states more than fluctuations in affect. Journal of Research in Personality. (in press).

Wilson RS, Krueger KR, Gu L, Bienias JL, Mendes de Leon CF, Evans DA. Neuroticism, extraversion, and mortality in a defined population of older persons. Psychosomatic Medicine. 2005; 67:841845. [PubMed: 16314587] 
World Health OrganizationMental health action plan 2013-2020Geneva: World Health Organization; 2013

Wrzus C, Hanel M, Wagner J, Neyer FJ. Social network changes and life events across the life span: a meta-analysis. Psychological Bulletin. 2013; 139:53-80. [PubMed: 22642230]

Wrzus C, Wagner GG, Riediger M. Personality-situation transactions from adolescence to old age. Journal of Personality and Social Psychology. 2016; 110:782-799. [PubMed: 26167797]

Zaider TI, Heimberg RG, Iida M. Anxiety disorders and intimate relationships: a study of daily processes in couples. Journal of Abnormal Psychology. 2010; 119:163-173. [PubMed: 20141253]

Zaki J, Williams WC. Interpersonal emotion regulation. Emotion. 2013; 13:803-810. [PubMed: 24098929]

Zautra AJ, Affleck GG, Tennen H, Reich JW, Davis MC. Dynamic approaches to emotions and stress in everyday life: Bolger and Zuckerman reloaded with positive as well as negative affects. Journal of Personality. 2005; 73:1511-1538. [PubMed: 16274444]

Zhu X, Woo SE, Porter C, Brzezinski M. Pathways to happiness: From personality to social networks and perceived support. Social Networks. 2013; 35:282-293.

Zinbarg RE, Mineka S, Bobova L, Craske MG, Vrshek-Schallhorn S, Griffith JW, Anand D. Testing a hierarchical model of neuroticism and its cognitive facets: Latent structure and prospective prediction of first onsets of anxiety and unipolar mood disorders during 3 years in late adolescence. Clinical Psychological Science. 2016; 4:805-824.

ZuckermanM. General and situation-specific traits and states: new approaches to assessment of anxiety and other constructs. In: ZuckermanM, , SpielbergerCD, editorsEmotions and anxiety: new concepts, methods and applicationsHillsdale, NJ: Lawrence Erlbaum; 1976133174

Emotion. Author manuscript; available in PMC 2018 November 01. 

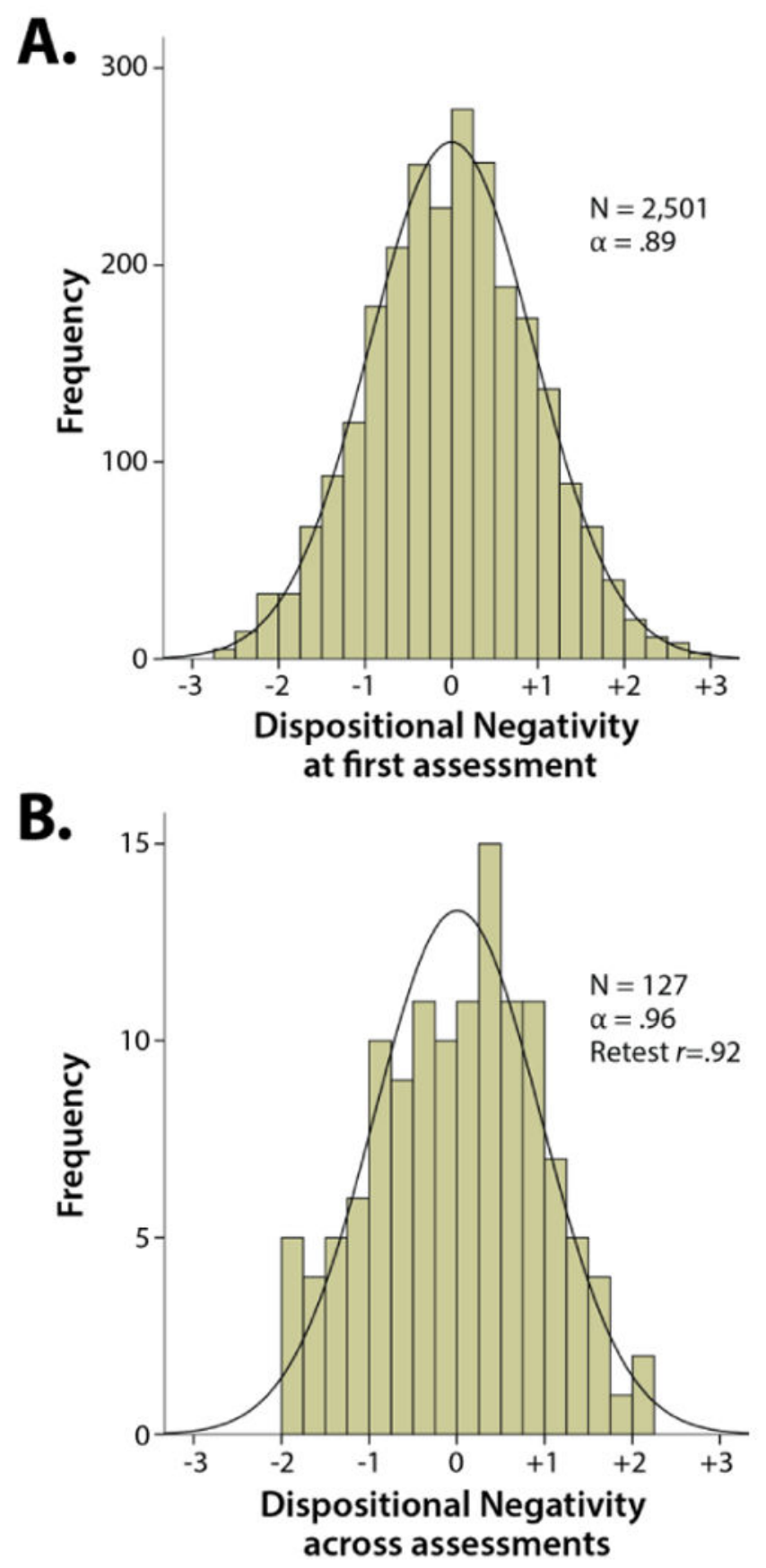

Figure 1. Psychometric characteristics of dispositional negativity

As detailed in the Methods, a composite measure of dispositional negativity was computed using well-established measures of neuroticism (John et al., 2008) and trait anxiety

(Goldberg, 1999; Goldberg et al., 2006). A. Screening sample. The composite measure of dispositional negativity was highly reliable $(a=.89)$. Dispositional negativity in the screening sample $(n=2,501)$ was stratified by tertile and sex to produce six sampling strata (not depicted). B. EMA sub-sample. For the EMA study ( $n=127)$, subjects were independently and randomly recruited from each of the six strata, enabling us to capture a broad range of 
dispositional negativity while balancing sex. As part of the EMA study, dispositional negativity was assessed a second time. EMA hypothesis testing employed the mean level of dispositional negativity across assessments, minimizing the influence of occasion-specific fluctuations in responding. This composite showed high levels of internal-consistency and test-retest reliability ( $\mathrm{a}=.96 ; r=.92 ; M=115.5$ days, $S D=61.0$ days). 


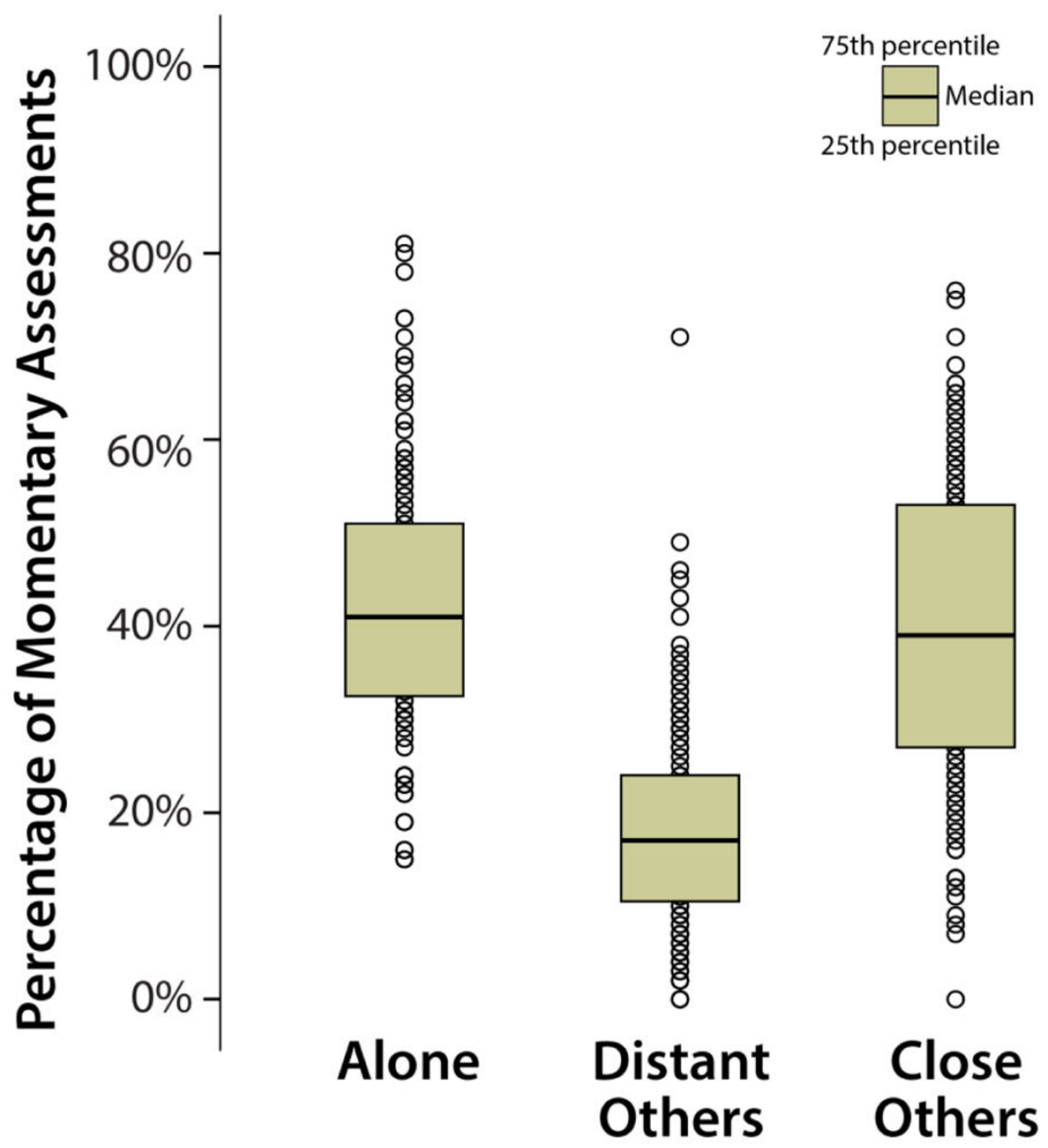

Figure 2. Percentage of momentary assessments completed in each social environment Rectangles indicate the median and inter-quartile range. Open circles depict individual subjects. 
Negative Experience
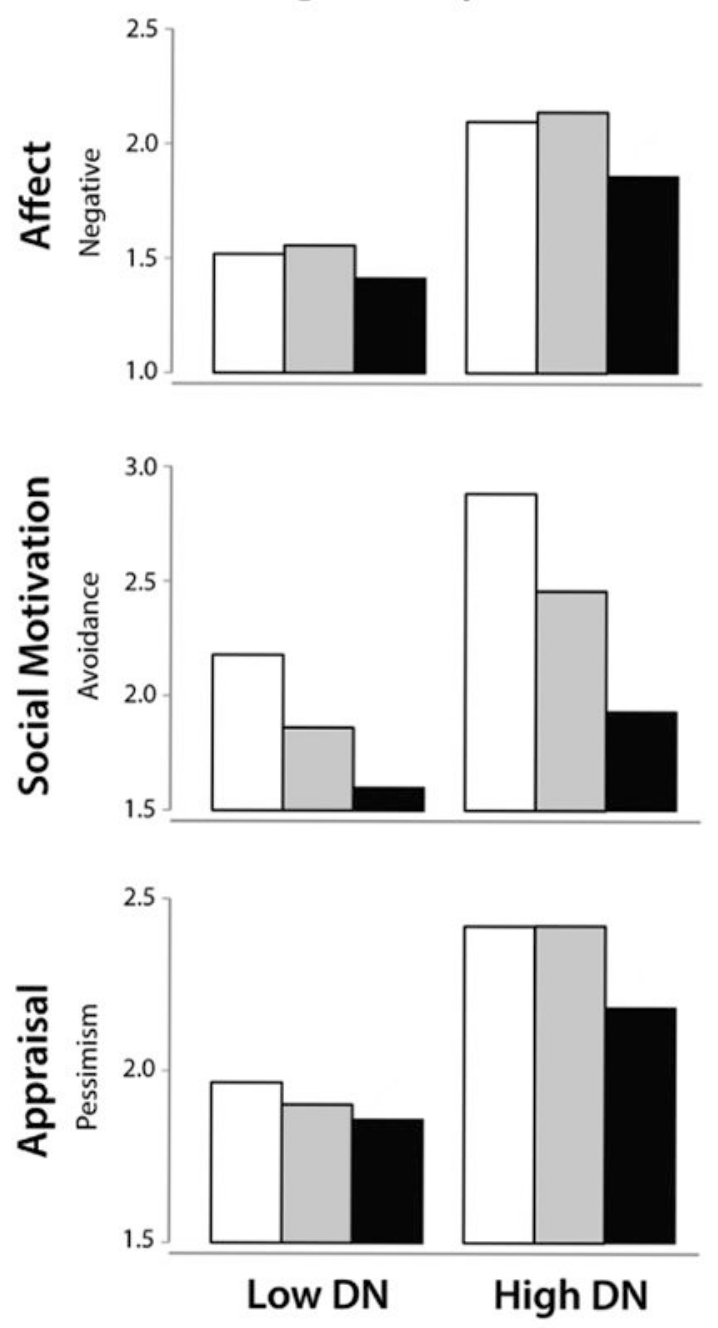
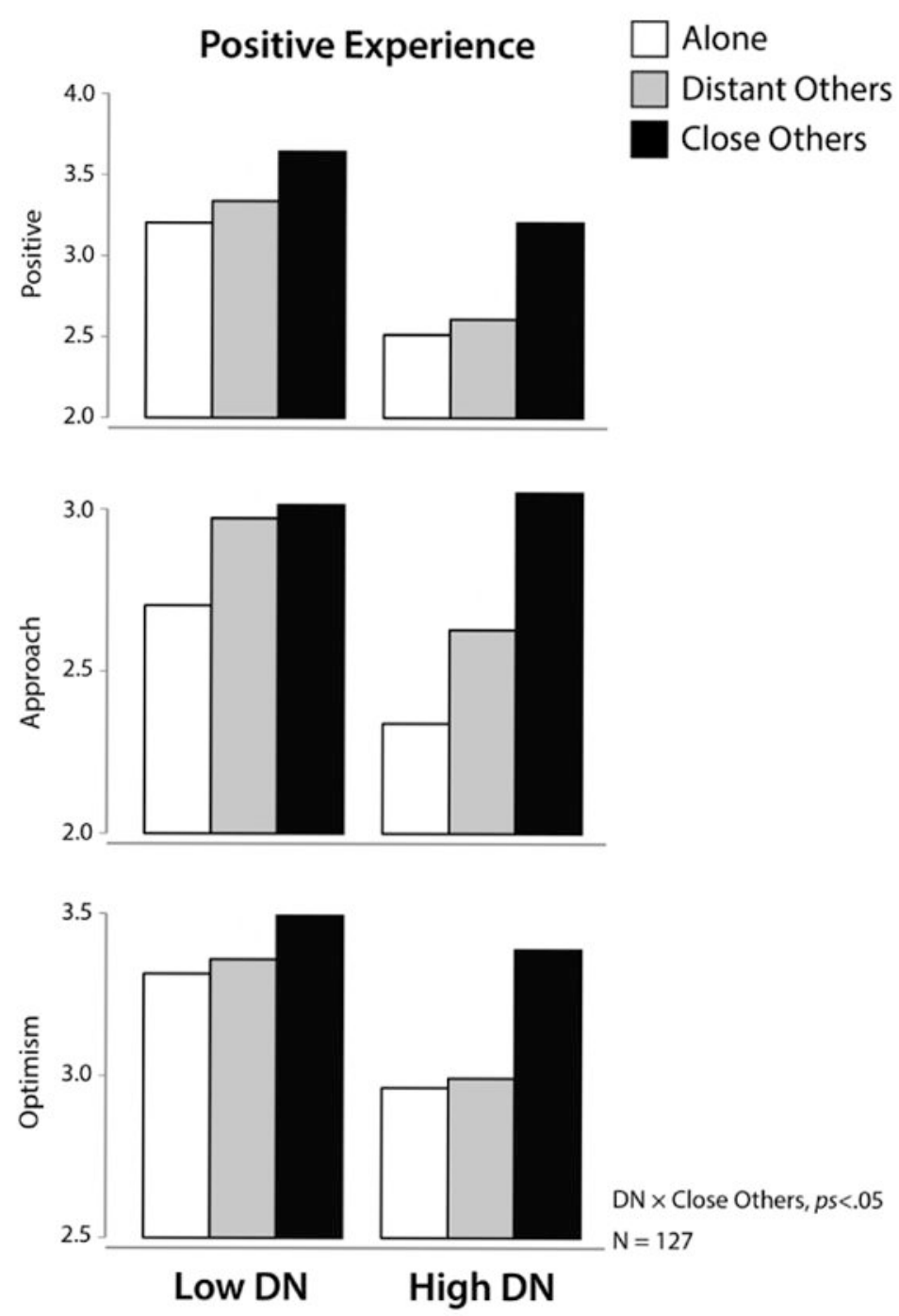

Figure 3. EMA demonstrates that the deleterious impact of dispositional negativity on momentary experience critically depends on social context

Individuals with high levels of dispositional negativity reap larger benefits-larger decrements in negative experience (left side of display) and larger increments in positive experience (right side of display) — from the company of Close Others (black bars), relative to being Alone (white bars). See Table 1 and Supplementary Table 2 for detailed results. Follow-up analyses demonstrated that the presence of Close Others provided significantly greater benefits than Distant Others. Hypothesis testing relied on a continuous measure of dispositional negativity. For illustrative purposes, predicted values derived from the MLMs are depicted for extreme levels $( \pm 1 S D)$. DN: Dispositional negativity. 


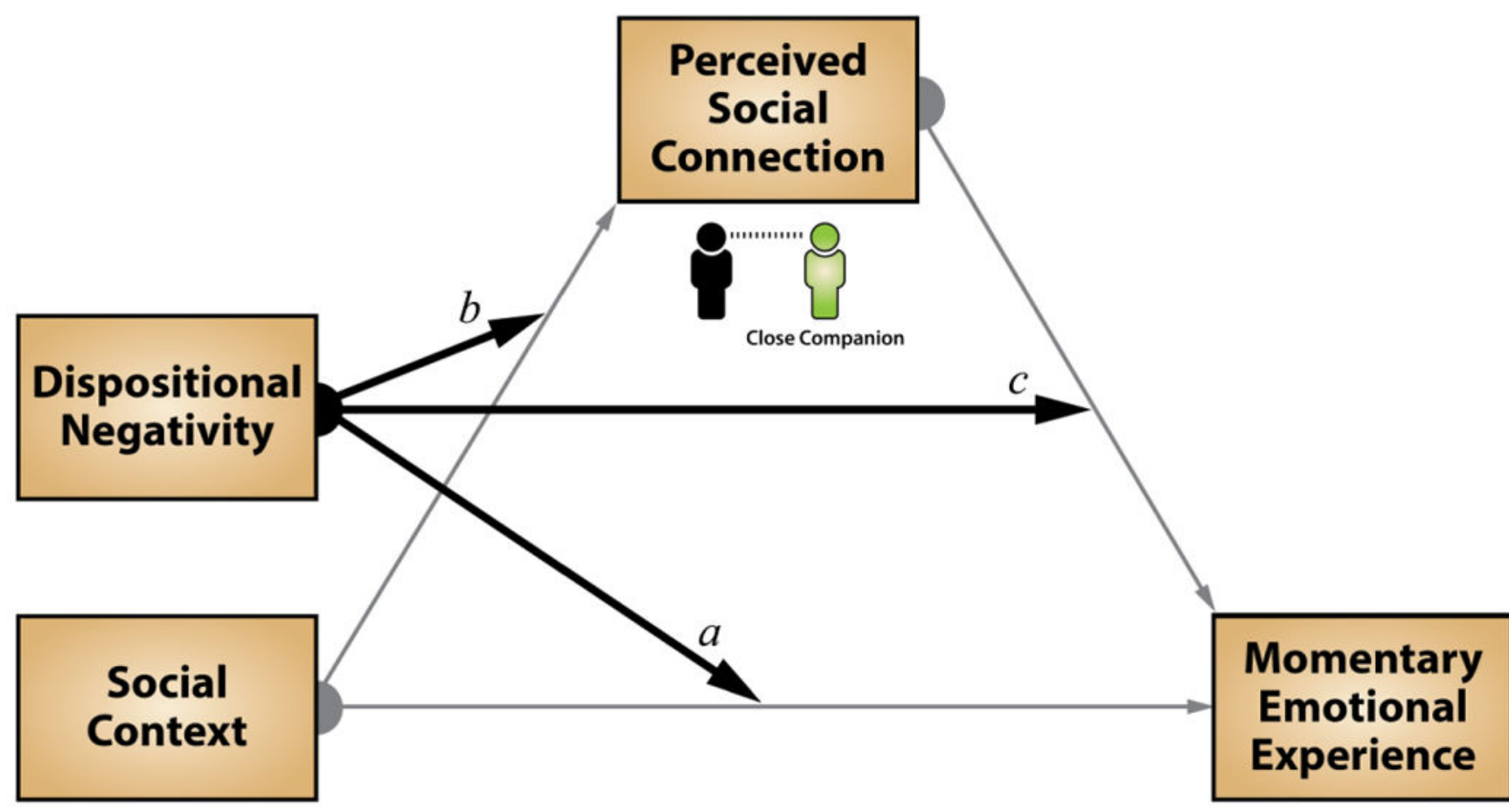

Figure 4. Moderated mediation framework

Our results demonstrate that dispositional negativity and social context interactively determine the quality of momentary experience (path a). Individuals with a more negative disposition derive larger emotional benefits from the company of close companions. Elevated levels of dispositional negativity are associated with a reduction in the quality of momentary emotional experience, but the presence of other individuals, especially close companions, markedly attenuates this association. We hypothesized that this 'buffering' effect reflects momentary variation in the degree of perceived social connection. A moderated mediation framework was used to assess specific aspects of this hypothesis (e.g., paths $b$ and $c$ ) (Hayes, 2013). Black paths indicate moderation and gray paths indicate mediation. 


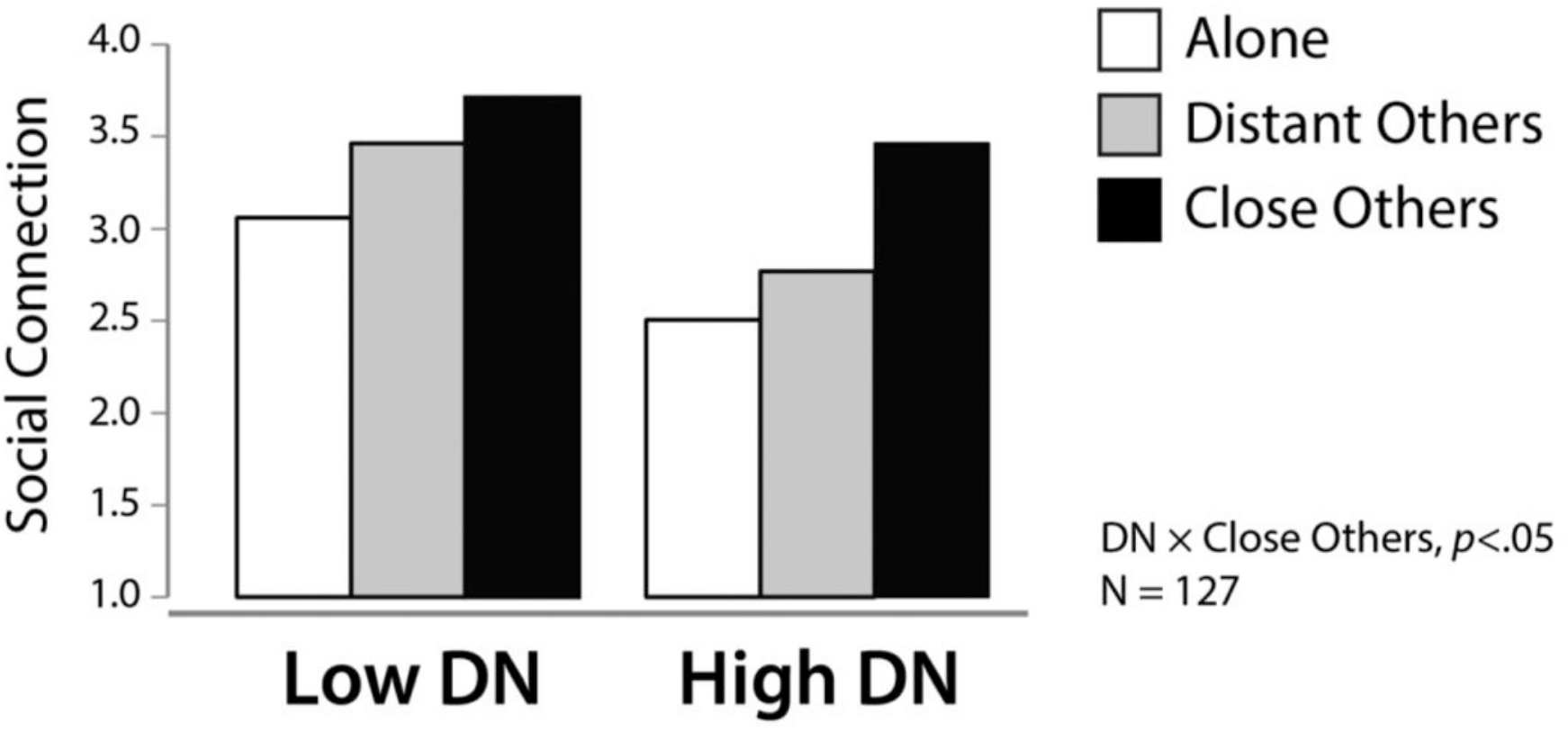

Figure 5. The deleterious impact of dispositional negativity on perceived social connection is conditional on social context

MLM results indicate that individuals with a more negative disposition are hyper-sensitive to the social environment, experiencing amplified feelings of social connection in the company of Close Others (black bars) relative to Alone (white bars) and attenuated feelings of social connection in the presence of Distant Others (gray bars) relative to Alone (white bars). Hypothesis testing relied on a continuous measure of dispositional negativity. For illustrative purposes, predicted values are depicted for extreme levels $( \pm 1 S D)$. DN: Dispositional negativity. 

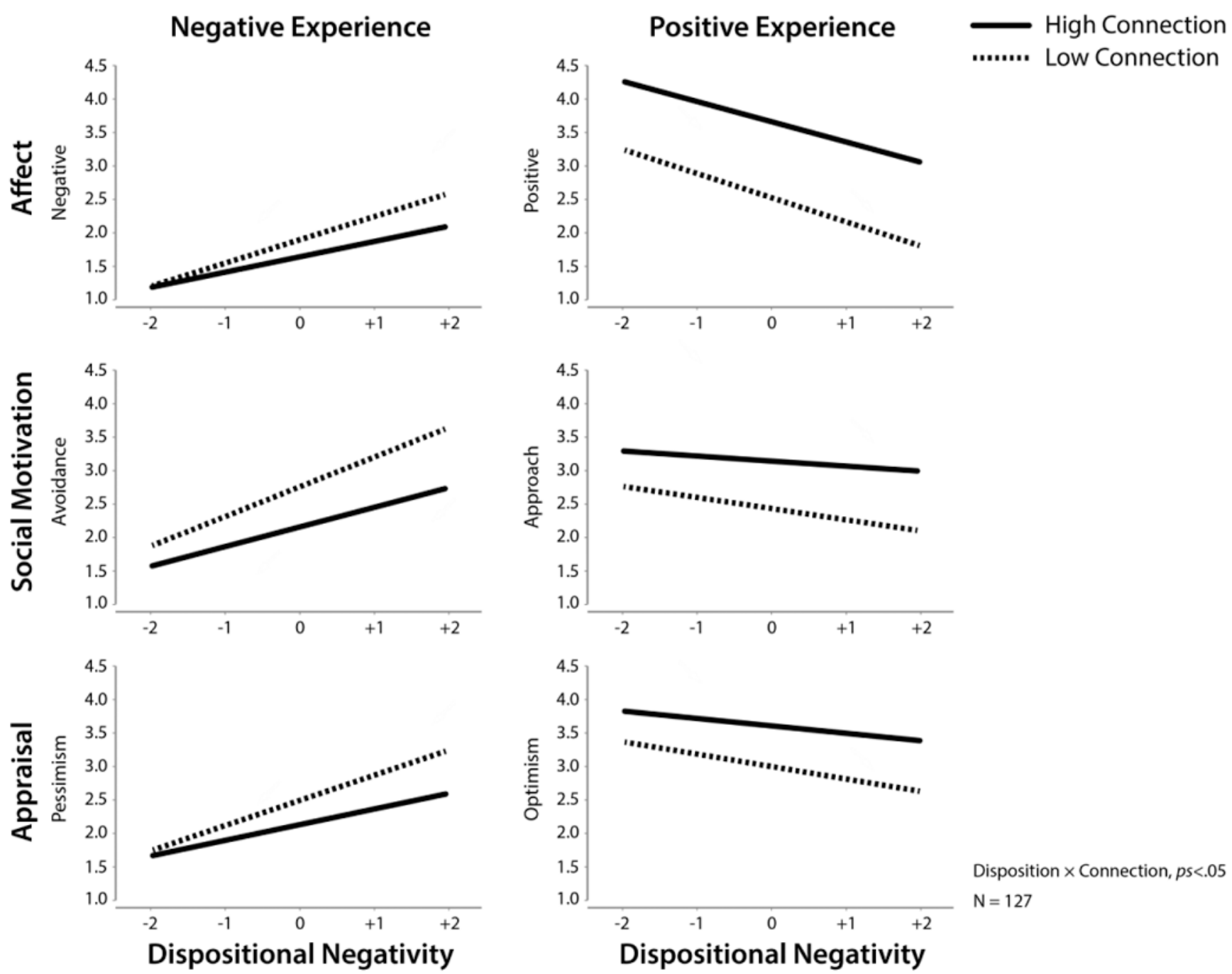

Figure 6. Momentary fluctuations in perceived social connection govern the adverse impact of dispositional negativity on emotional experience

Simple effects analyses demonstrated that the adverse impact of dispositional negativity on momentary experience is attenuated - the regression slope is flatter-during moments when social connection was high (solid line) relative to when it was low (broken line), particularly for negative affect, social avoidance, and pessimism. Individuals with a more negative disposition derive larger emotional benefits from perceived social connection compared to those with a less negative disposition (i.e., the difference between the solid and broken lines is magnified at high levels of negativity). See Tables 3 and 4 for detailed results. Hypothesis testing relied on continuous measures of social connection and dispositional negativity. For illustrative purposes, predicted values are depicted for extreme levels $( \pm 1 S D)$ of social connection. 


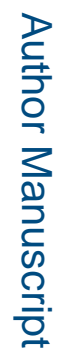

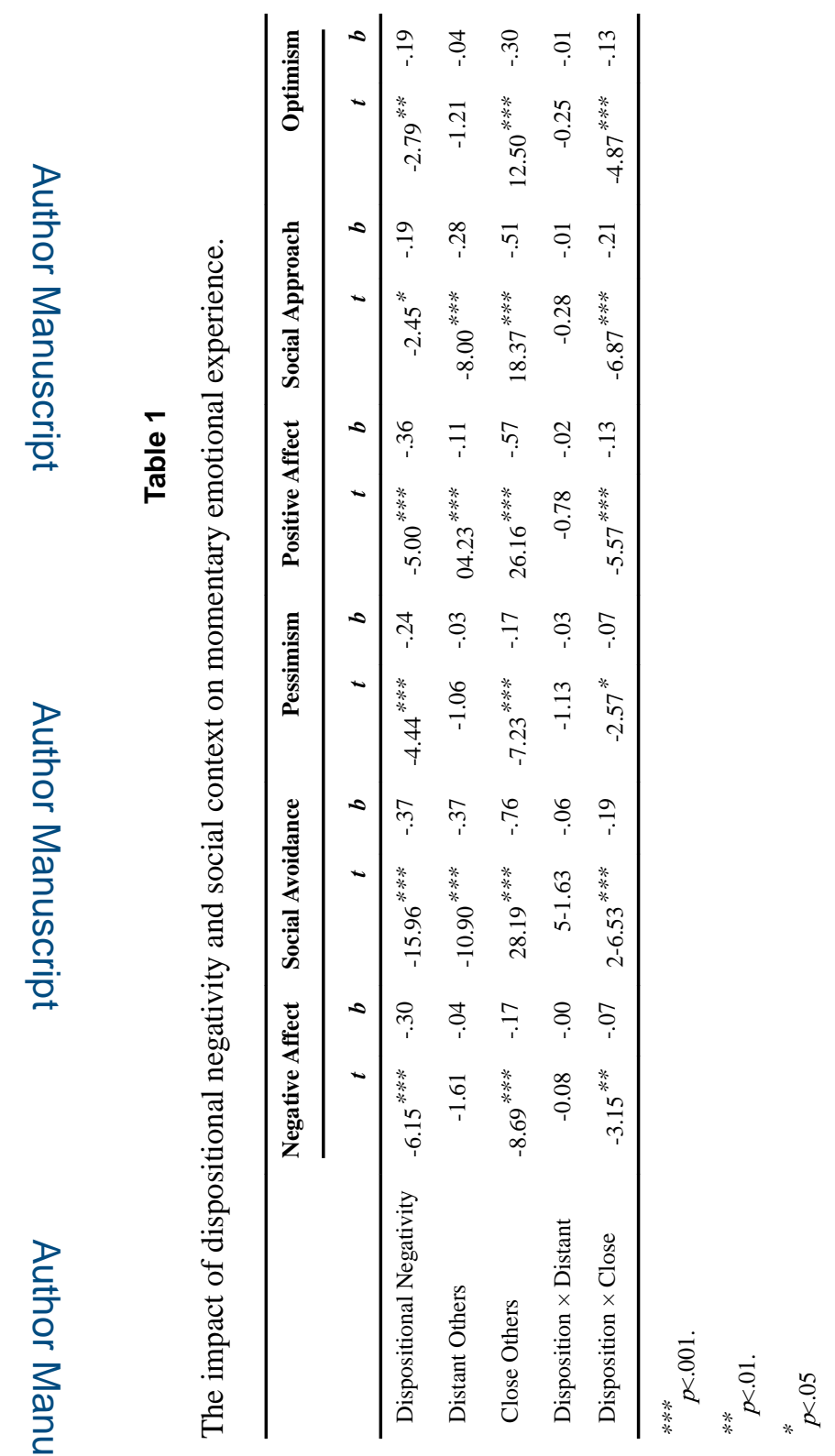

Emotion. Author manuscript; available in PMC 2018 November 01. 


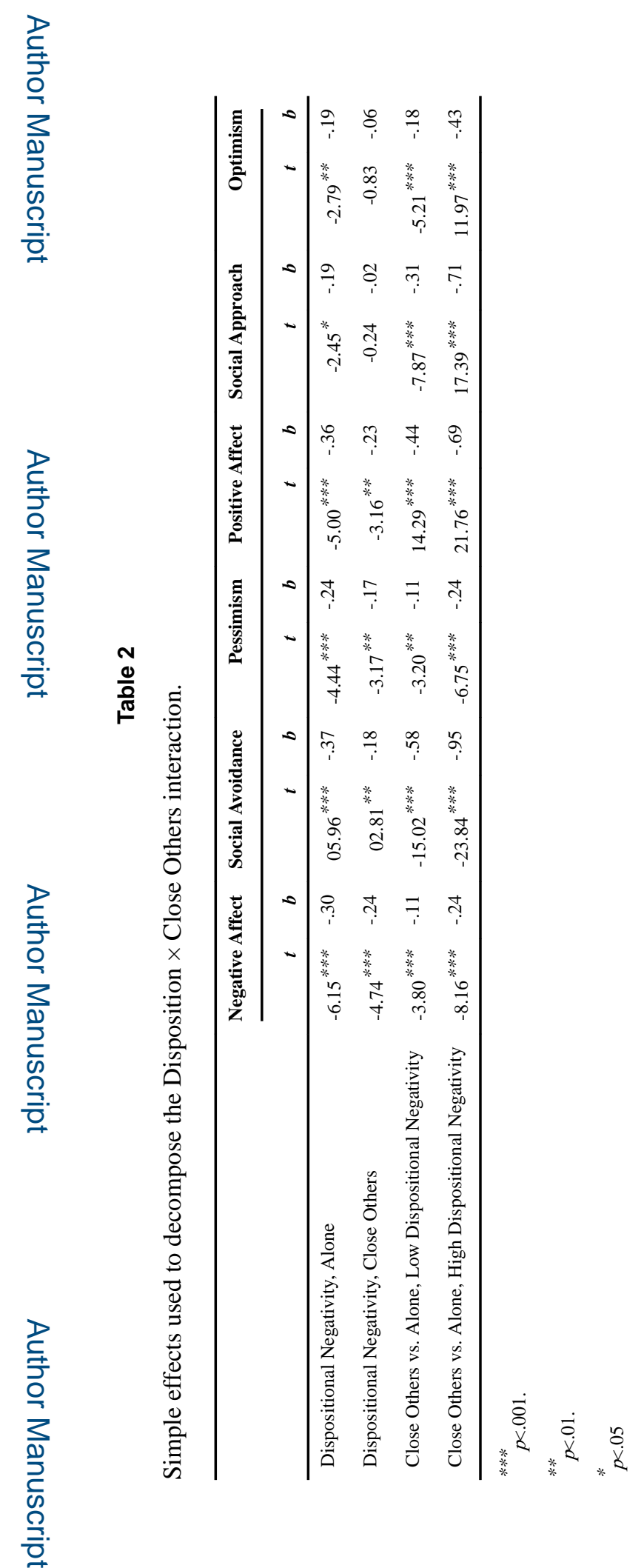

Emotion. Author manuscript; available in PMC 2018 November 01. 


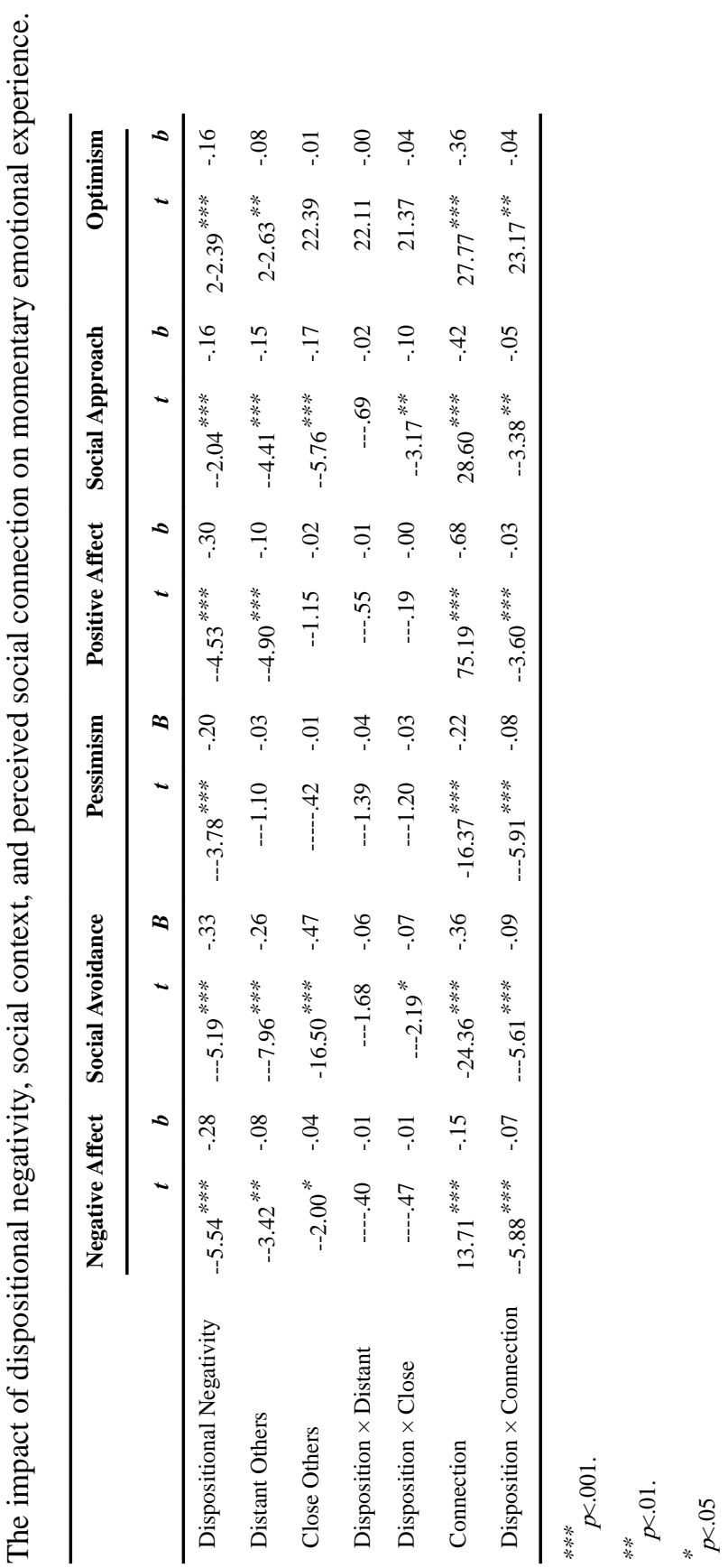




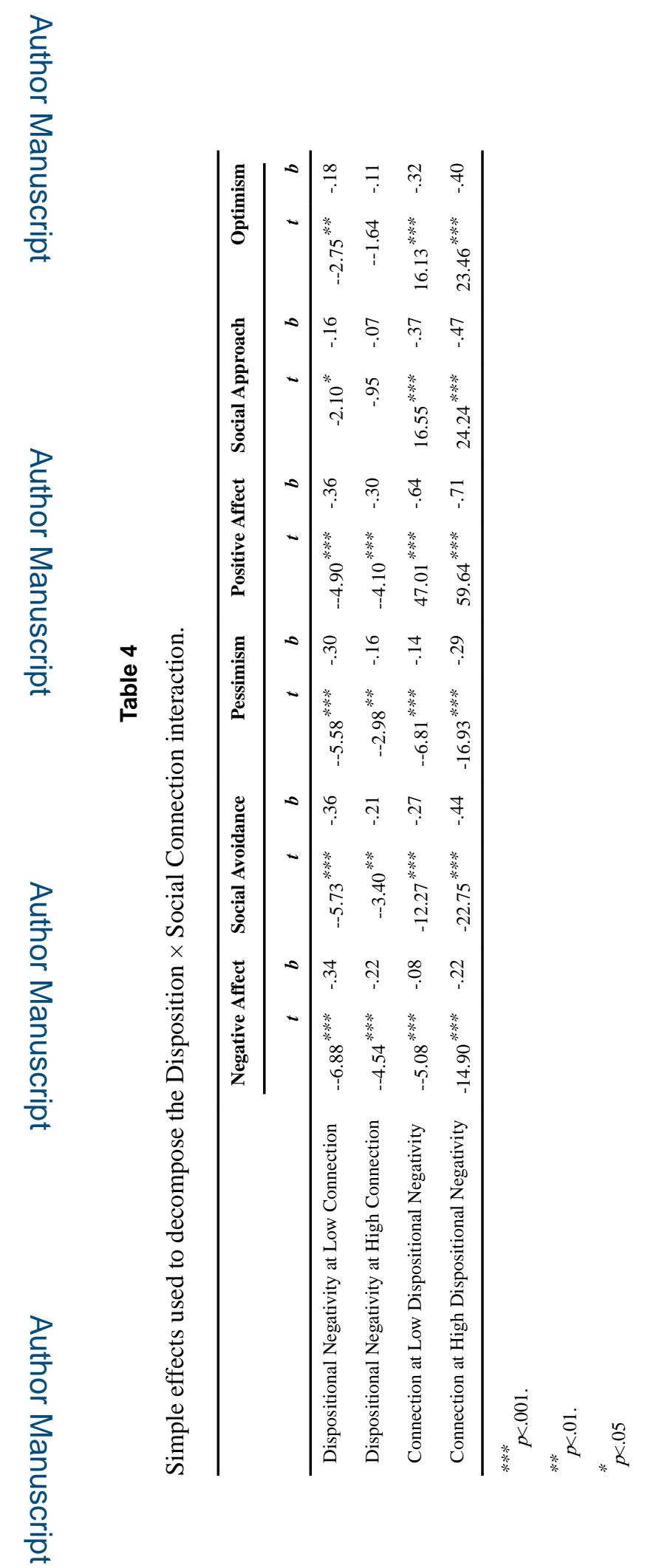

Emotion. Author manuscript; available in PMC 2018 November 01. 


\section{로을}

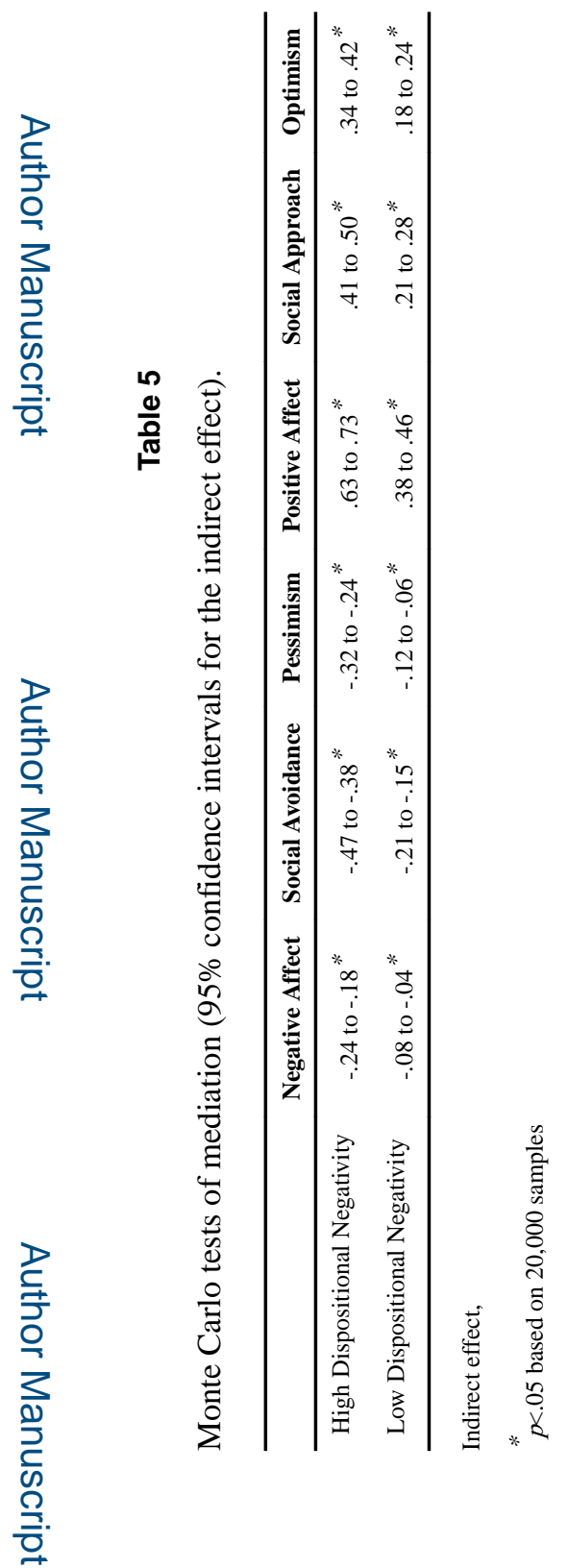

Emotion. Author manuscript; available in PMC 2018 November 01. 